\title{
Discussão dos limites das propriedades térmicas dos fechamentos opacos segundo as normas de desempenho térmico brasileiras
}

\author{
Discussion of the limits of the thermal properties of \\ building envelopes according to Brazilian thermal \\ performance standards
}

\section{Camila Carvalho Ferreira \\ Henor Artur de Souza \\ Eleonora Sad de Assis}

\section{Resumo \\ A}

s normas de desempenho térmico de edificações têm como um de seus objetivos avaliar a envoltória da edificação, identificando aquelas edificações que são adequadas e que irão garantir um desempenho mínimo no qual seus usuários possam sentir-se em conforto.

Atualmente, estão em vigor no Brasil duas normas que abordam o desempenho das edificações: a NBR 15220 (2005) e a NBR 15575 (2013). Alguns estudos apontam inconsistências nessas normas, principalmente no que se refere aos valores-limite estabelecidos para as características termofísicas das paredes e coberturas. O objetivo deste trabalho é avaliar o conforto térmico de uma edificação residencial multifamiliar adotando os valores-limite de Mahoney, comparando os resultados com os obtidos a partir dos valores normativos para cada uma das zonas bioclimáticas. A análise foi realizada por meio de simulações no EnergyPlus ${ }^{\odot}$ para o período de 1 ano em 24 cidades brasileiras. Os resultados indicaram a necessidade de revisão, principalmente dos valores adotados para a capacidade térmica das paredes e para a transmitância térmica e a absortância solar das coberturas da norma NBR 15220. Além disso, há a necessidade de rever valores da capacidade térmica das paredes e da capacidade térmica e da absortância solar das coberturas no caso da norma NBR 15575.

Palavras-chaves: Simulação de desempenho térmico. Normas de desempenho térmico. Propriedades termofísicas da envoltória.

\begin{abstract}
One of the purposes of thermal performance standards for buildings is to evaluate the building envelope, identifying those building that are appropriate and can guarantee a minimum performance and hence the thermal comfort of users. In Brazil, there are currently two standards that regulate the thermal performance of residential buildings: NBR 15220 (2005) and NBR 15575 (2013). Some studies point out inconsistencies in these standards, especially with regard to the limit values for the thermo-physical characteristics of walls and roofs. The aim of this paper is to evaluate the thermal comfort of a multifamily residential building, adopting Mahoney's limit values, comparing these results with those obtained through the normative values for each of Brazil's bioclimatic zones. The analysis was performed through simulations using EnergyPlus ${ }^{\circledR}$ during one year in 24 Brazilian cities. The results point to the need to review especially the values adopted for the thermal capacity of walls and the thermal transmittance and solar absorptance of envelopes in NBR 15220 (2005), as well as the need to establish values for the thermal capacity of walls and the thermal capacity and solar absorptance of envelopes in the case of NBR 15575.
\end{abstract}

Eleonora Sad de Assis Universidade Federal de Minas Gerais Belo Horizonte - MG - Brasil

Recebido em 26/03/16 Aceito em 18/07/16
Keywords: Thermal performance simulation. Thermal performance standards. Envelope thermo-physical characteristics. 


\section{Introdução}

A normalização de desempenho térmico objetiva avaliar e regulamentar um padrão mínimo de desempenho para as edificações, garantindo condições de habitabilidade e conforto delas. Para garantir um desempenho térmico mínimo, as normas brasileiras atuais com esse enfoque delimitam os ganhos através das superfícies externas opacas, principalmente, estabelecendo valores-limite para as características termofísicas de transmitância, absortância e capacidade térmica.

A primeira norma brasileira de desempenho instituída foi a NBR 15220 (ABNT, 2005), tendo como ênfase a avaliação de habitações unifamiliares de interesse social com até três pavimentos. É nessa norma que o zoneamento bioclimático brasileiro é proposto, baseado no Diagrama de Givoni, tendo gerado, assim, recomendações de projeto para cada uma das oito zonas bioclimáticas. Sobre a envoltória, essa norma estabelece três tipos de paredes (leve, leve refletora e pesada) e três tipos de coberturas (leve isolada, leve refletora e pesada), a serem eleitas conforme as condições climáticas da zona bioclimática. Para cada tipo de parede e cobertura foram determinados valores-limite de transmitância térmica, atraso térmico e fator solar (função da transmitância térmica e da absortância à radiação solar). As demais recomendações de projeto constantes nessa norma referem-se ao tamanho das aberturas para ventilação natural e à necessidade de sombreamento, além de indicações sobre a necessidade de condicionamento artificial e demais estratégias bioclimáticas, como o emprego de inércia térmica de paredes internas e resfriamento passivo.

Com o intuito de ampliar a abrangência da avaliação de desempenho térmico de edificações, em 2008 foi publicada a NBR 15575 - Edifícios habitacionais de até cinco pavimentos: desempenho, revista em 2013 e publicada como NBR 15575 - Edifícios habitacionais: desempenho (ABNT, 2013). Essa norma compreende o desempenho da edificação em vários aspectos, entre os quais o desempenho térmico. A respeito do desempenho térmico, a norma estabelece três procedimentos de avaliação: simplificado (ou prescritivo), simulação e medição. $\mathrm{O}$ procedimento simplificado verifica o atendimento de critérios mínimos referentes às características termofísicas de transmitância e capacidade térmica, para os sistemas de fechamento e de cobertura, conforme o estabelecido nas partes 4 e 5 da norma em questão.
Tanto os valores-limite da norma NBR 15220 quanto os da NBR 15575 são apresentados na Tabela 1.

Uma análise dos valores apresentados na Tabela 1 permite observar que, apesar de ambas as normas, a NBR 15220 e a NBR 15575, abordarem o desempenho térmico de edificações residenciais e ambas se basearem no zoneamento bioclimático brasileiro, existem incongruências entre os valoreslimite de cada norma para uma mesma zona bioclimática. Outro ponto de incongruência se refere à inércia térmica. Enquanto a NBR 15220 aborda a questão restringindo o valor do atraso térmico a um valor máximo para "paredes leves" e "leves refletoras", e um valor mínimo para as "paredes pesadas", a NBR 15575 define apenas um valor mínimo para a capacidade térmica. Em outras palavras, as normas abordam a inércia térmica de forma divergente. É importante colocar que a NBR 15220 foi desenvolvida enfocando habitações de interesse social de até três pavimentos, podendo não ser capaz de abranger edificações residenciais de outras tipologias. Apesar disso, avaliando os valores-limite da transmitância térmica da envoltória, observa-se que os valores da NBR 15220 são mais restritivos do que os da NBR 15575.

Diversos estudos realizados apontam discrepâncias entre os valores-limite normativos estabelecidos e o bom desempenho térmico da edificação e o conforto térmico do usuário.

Pereira e Assis (2005) realizaram um estudo acerca da adequação das recomendações de projeto propostas pela NBR 15220 para a cidade de Belo Horizonte, inserida na Zona Bioclimática 3, e constataram que o valor da transmitância térmica sugerido pela norma é mais elevado do que o valor que seria adequado. Também com referência a essa norma, Bogo (2008) argumenta que o valor da transmitância térmica de $2,00 \mathrm{~W} / \mathrm{m} 2 \mathrm{~K}$ é um valor alto para as coberturas classificadas como "leve e isolada". No estudo conduzido por Matos (2007), cujo enfoque foi habitações com o uso de ventilação natural situadas na cidade de Florianópolis, os resultados obtidos permitiram à autora concluir que alguns limites estabelecidos pela norma NBR 15220 para o atraso térmico não se justificam, uma vez que valores de atraso térmico superiores ao limite estabelecido pela norma resultaram em melhor desempenho térmico. No trabalho desenvolvido por Oliveira (2012), o 
autor analisou a pertinência dos valores recomendados pela norma NBR 15220 (ABNT, 2005), como limites para a transmitância térmica, atraso térmico e fator de calor solar para as paredes externas e coberturas. Observou-se que, para se obterem as melhores condições de conforto, valores mais elevados do que os limites da norma NBR15220 (ABNT, 2005) para a Zona 2 de atraso térmico e de absortância resultaram em melhores condições para o interior da edificação (OLIVEIRA, 2012).

Tabela 1 - Valores-limite para as características termofísicas segundo as normas NBR 15220 e NBR 15575

\begin{tabular}{|c|c|c|c|c|c|c|c|c|c|}
\hline \multicolumn{10}{|c|}{ DESEMPENHO TÉRMICO DE PAREDES } \\
\hline & Zona Bioclimática & ZB1 & ZB2 & ZB3 & ZB4 & ZB5 & ZB6 & ZB7 & ZB8 \\
\hline \multirow{4}{*}{ 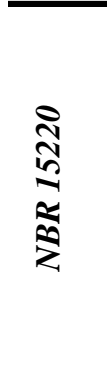 } & $\begin{array}{l}\text { Transmitância } \\
\text { térmica }-\mathrm{U} \\
\left(\mathrm{W} / \mathrm{m}^{2} \mathrm{~K}\right)\end{array}$ & \multicolumn{2}{|c|}{$\mathrm{U} \leq 3,00$} & $\mathrm{U} \leq 3,60$ & $\mathrm{U} \leq 2,20$ & $\mathrm{U} \leq 3,60$ & \multicolumn{2}{|c|}{$\mathrm{U} \leq 2,20$} & $\mathrm{U} \leq 3,60$ \\
\hline & $\begin{array}{l}\text { Atraso térmico - } \\
\varphi(\mathrm{h})\end{array}$ & \multicolumn{2}{|c|}{$\varphi \leq 4,3$} & $\varphi \leq 4,3$ & $\varphi \geq 6,5$ & $\varphi \leq 4,3$ & \multicolumn{2}{|c|}{$\varphi \geq 6,5$} & $\varphi \leq 4,3$ \\
\hline & $\begin{array}{l}\text { Fator solar }-\mathrm{FS}_{\mathrm{o}} \\
(\%)\end{array}$ & \multicolumn{2}{|c|}{$\mathrm{FS}_{\mathrm{o}} \leq 5,0$} & $\mathrm{FS}_{\mathrm{o}} \leq 4,0$ & $\mathrm{FS}_{\mathrm{o}} \leq 3,5$ & $\mathrm{FS}_{\mathrm{o}} \leq 4,0$ & \multicolumn{2}{|c|}{$\mathrm{FS}_{\mathrm{o}} \leq 3,5$} & $\mathrm{FS}_{\mathrm{o}} \leq 4,0$ \\
\hline & $\begin{array}{l}\text { Absortância solar } \\
-\alpha^{1}\end{array}$ & \multicolumn{2}{|c|}{$\alpha \leq 0,4$} & $\alpha \leq 0,3$ & $\alpha \leq 0,4$ & $\alpha \leq 0,3$ & \multicolumn{2}{|c|}{$\alpha \leq 0,4$} & $\alpha \leq 0,3$ \\
\hline \multirow{3}{*}{$\begin{array}{l}n \\
\hat{n} \\
\frac{n}{2} \\
\frac{1}{z}\end{array}$} & Transmitância & \multirow{2}{*}{\multicolumn{2}{|c|}{$\mathrm{U} \leq 2,50$}} & \multicolumn{6}{|c|}{$\mathrm{U} \leq 3,70$ para $\alpha \leq 0,6$} \\
\hline & $\begin{array}{l}\text { termica }-U \\
\left(\mathrm{~W} / \mathrm{m}^{2} \mathrm{~K}\right)\end{array}$ & & & \multicolumn{6}{|c|}{$\mathrm{U}<2,50$ para $\alpha>0,6$} \\
\hline & $\begin{array}{l}\text { Capacidade } \\
\text { térmica - CT } \\
\left(\mathrm{kJ} / \mathrm{m}^{2} \mathrm{~K}\right) \\
\end{array}$ & \multicolumn{7}{|c|}{$\mathrm{CT} \geq 130$} & - \\
\hline \multicolumn{10}{|c|}{ DESEMPENHO TÉRMICO DE COBERTURAS } \\
\hline & Zona Bioclimática & ZB1 & $\mathbf{Z B 2}$ & ZB3 & ZB4 & ZB5 & ZB6 & ZB7 & ZB8 \\
\hline \multirow{4}{*}{ 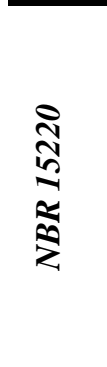 } & $\begin{array}{l}\text { Transmitância } \\
\text { térmica - U } \\
\left(\mathrm{W} / \mathrm{m}^{2} \mathrm{~K}\right)\end{array}$ & \multicolumn{6}{|c|}{$\mathrm{U} \leq 2,00$} & $\mathrm{U} \leq 2,00$ & $\mathrm{U} \leq 2,30 . \mathrm{FT}^{1}$ \\
\hline & $\begin{array}{l}\text { Atraso térmico - } \\
\varphi(\mathrm{h})\end{array}$ & \multicolumn{6}{|c|}{$\varphi \leq 3,3$} & $\varphi \geq 6,5$ & $\varphi \leq 3,3$ \\
\hline & $\begin{array}{l}\text { Fator solar }-\mathrm{FS}_{\mathrm{o}} \\
(\%)\end{array}$ & \multicolumn{6}{|c|}{$\mathrm{FS}_{\mathrm{o}} \leq 6,5$} & $\mathrm{FS}_{\mathrm{o}} \leq 6,5$ & $\mathrm{FS}_{\mathrm{o}} \leq 6,5$ \\
\hline & $\begin{array}{l}\text { Absortância solar } \\
-\alpha^{1}\end{array}$ & \multicolumn{6}{|c|}{$\alpha \leq 0,8$} & $\alpha \leq 0,8$ & $\alpha \leq 0,7$ \\
\hline \multirow{2}{*}{ 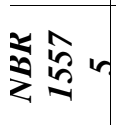 } & Transmitância & \multirow{2}{*}{\multicolumn{2}{|c|}{$\mathrm{U} \leq 2,30$}} & \multicolumn{4}{|c|}{$\mathrm{U} \leq 2,30$ para $\alpha \leq 0,6$} & \multicolumn{2}{|c|}{$\mathrm{U} \leq 2,30 \mathrm{FT}^{2}$ para $\alpha \leq 0,4$} \\
\hline & $\begin{array}{l}\text { térmica }-\mathrm{U} \\
\left(\mathrm{W} / \mathrm{m}^{2} \mathrm{~K}\right)\end{array}$ & & & \multicolumn{4}{|c|}{$\mathrm{U}<1,50$ para $\alpha>0,6$} & \multicolumn{2}{|c|}{$\mathrm{U}>1,50 \mathrm{FT}^{2}$ para $\alpha>0,4$} \\
\hline
\end{tabular}

Fonte: adaptada da NBR 15220 (ABNT, 2005) e da NBR 15575 (ABNT, 2013).

Nota: ${ }^{1}$ Calculada a partir da equação $\mathrm{FS}_{0}=4$.U.a (ABNT, 2005), considerando os valores-limite da transmitância térmica e de fator de ganho de calor solar de elementos opacos; e ${ }^{2} \mathrm{FT}=1,17-1,07 \mathrm{~h}^{-1,04}$. 
Estudos referentes à norma NBR 15575 (ABNT, 2013) também têm sido conduzidos. Pereira e Ferreira (2014) realizaram uma avaliação de desempenho térmico de uma edificação multifamiliar segundo os critérios da Norma 15575 (ABNT, 2013) e o critério de conforto da ASHRAE 55 (AMERICAN..., 2013), em diferentes zonas bioclimáticas, e os resultados mostraram que há dissociação entre o desempenho e o conforto térmico. Chvatal (2014) comparou o procedimento de avaliação simplificado para desempenho térmico proposto pela norma e o comparou com os resultados obtidos para o método de simulação. Os resultados obtidos pela autora indicaram que o procedimento simplificado não é sensível aos impactos da transmitância e da absortância da envoltória como o método de simulação, podendo originar uma classificação de desempenho equivocada. Além disso, a autora também observou que a capacidade térmica influencia os limites dessas variáveis, não devendo os parâmetros termofísicos ser avaliados de forma desassociada (CHVATAL, 2014). Soares (2014) avaliou as prescrições da norma NBR 15575 (ABNT, 2013) para a Zona Bioclimática 2 para uma habitação de interesse social e concluiu que os limites dos parâmetros termofísicos propostos pela norma mostraram-se muito elevados. Ferreira, Souza e Assis (2015) avaliaram o conforto térmico de uma edificação residencial multifamiliar adotando os valores-limite normativos das normas NBR 15220 (ABNT, 2005) e NBR 15575 (ABNT, 2013) para cada uma das zonas bioclimáticas brasileiras. Além dos valores normativos, foram também avaliados os valores-limite para as características termofísicas das paredes e coberturas segundo Mahoney (KOENIGSBERGER; MAHONEY; EVANS, 1970). Os resultados indicaram que os valoreslimite para as características termofísicas das paredes e coberturas propostos pelas tabelas de Mahoney geram melhores condições de conforto para os casos analisados, superando o desempenho dos valores normativos. As simulações realizadas mostram também que a absortância tem grande influência no desempenho térmico final da envoltória. Esse fato aponta para a necessidade de se considerar a associação das variáveis envolvidas na caracterização termofísica das envoltórias para a definição de valores-limite (FERREIRA; SOUZA; ASSIS, 2015).

Outro ponto relevante de se colocar é que em geral os métodos tradicionais vigentes de avaliação de desempenho térmico de edificações com caráter prescritivo tendem a ser baseados quase que estritamente em parâmetros como a resistência térmica ou a transmitância térmica.
Essa escolha se justifica sob condições próximas ao estado de regime permanente, em que há uma grande diferença entre a temperatura do ar externa e a interna, sendo esta última mantida praticamente constante por meio de climatização artificial. Nesse caso, o fluxo de calor depende principalmente da transmitância térmica da envoltória da edificação. Em edificações condicionadas naturalmente as trocas de calor ocorrem sob condições flutuantes, uma vez que os componentes da envoltória são aquecidos e resfriados periodicamente em função das variações de temperatura externa e da radiação solar incidente. Sob tais condições a capacidade térmica se torna a propriedade com efeito decisivo na determinação das condições térmicas internas.

As edificações residenciais brasileiras apresentam regime transiente segundo Akutsu e Vittorino (1997), e para tais condições os métodos tradicionais apresentam-se inadequados. No caso de climas quentes, como na maior parte do Brasil, em que boa parte das trocas de calor nas edificações ocorre por radiação, parâmetros como a ventilação e a radiação solar possuem relevância significativa para o conforto térmico. Ao se basear apenas na resistência térmica dos fechamentos nos métodos de avaliação, a contribuição da ventilação e da radiação é desconsiderada, principalmente no desempenho das edificações não condicionadas artificialmente (AKUTSU; VITTORINO, 1997).

Em razão do exposto, a resistência térmica e a transmitância térmica não se mostram apropriadas para avaliar o desempenho térmico das envoltórias de edificações condicionadas naturalmente em climas com grande amplitude térmica. Outros parâmetros, como a capacidade térmica e a absortância solar, têm-se mostrado mais apropriados (BARRIOS; HUELSZ; RECHTMAN, 2011).

Estudos como o de Pereira (2009), que avaliou a influência da envoltória no desempenho térmico de edificações residenciais unifamiliares ocupadas e ventiladas naturalmente em Florianópolis, apontam que $o$ envelope exerce influência sobre o desempenho térmico de edificações com tais características. No entanto, a propriedade que apresentou maior correlação com o conforto foi a capacidade térmica, e a pior correlação ocorreu para a transmitância térmica. Pode-se verificar que, para as condições do estudo, o mais indicado é a adoção de envelopes com maiores valores de capacidade e atraso térmicos (PEREIRA, 2009).

Pelo exposto, o presente artigo visa analisar a influência das propriedades termofísicas com maior impacto no desempenho térmico de 
edificações para diferentes contextos climáticos brasileiros, comparando os resultados obtidos com as recomendações normativas nacionais.

Para a análise de sensibilidade das propriedades termofísicas no desempenho térmico de uma edificação, será utilizado o experimento fatorial, a fim de estabelecer as variações necessárias.

\section{Método}

Para que a análise da influência das propriedades termofísicas no desempenho térmico fosse realizada, o desenvolvimento deste trabalho se baseou na simulação de uma edificação residencial multifamiliar, utilizando o programa EnergyPlus versão 8.1.0.008, para as diferentes conformações de envoltórias. As simulações foram realizadas para o período de 1 ano para três cidades brasileiras representativas de cada uma das oito zonas bioclimáticas. Os resultados de horas de conforto gerados são comparados, e, assim, identificadas as envoltórias com melhor desempenho térmico.

Para estabelecer as variações a serem realizadas nas envoltórias com o intuito de identificar as variáveis de maior influência, aplicou-se a estrutura do experimento fatorial, que permite avaliar não apenas o efeito das variáveis envolvidas na análise, mas também a interação entre elas. O número de fatores irá depender do número de variáveis e de níveis de experimentação. O tipo mais simples é o fatorial $2 \mathrm{k}$, terminologia derivada do fato de que apenas dois níveis para cada fator $\mathrm{k}$ são assumidos, um indicando o nível baixo (-) e o nível alto (+), ou indicando a presença ou ausência de um fator (REDDY, 2011).

A seguir as etapas do método serão descritas com melhor detalhamento.

\section{Objeto de estudo}

Em conformidade com as características atuais do mercado imobiliário brasileiro de construção, o estudo de caso foi definido como uma edificação residencial multifamiliar de cinco pavimentos e quatro apartamentos por andar, totalizando 20 apartamentos. Cada apartamento é composto de cinco cômodos (dormitório 1, dormitório 2, banheiro, sala, cozinha e área de serviço), conforme mostrado na Figura 1.

O ambiente analisado foi o dormitório 1 (destacado em vermelho, Figura 1), rotacionado para as quatro orientações principais: norte, leste, sul e oeste.

\section{Climas estudados}

Foram selecionadas 24 cidades brasileiras, três para cada zona bioclimática (ZB) definida na NBR 15220-3 (ABNT, 2005). As cidades escolhidas foram Maringá (PR), São Joaquim (SC) e Campos do Jordão (SP) para a Zona Bioclimática 1; Santa Maria (RS), Florestal (MG) e Teresópolis (RJ) para a Zona Bioclimática 2; Belo Horizonte (MG), Florianópolis (SC) e Ponta Porã (MS) para a Zona Bioclimática 3; Brasília (DF), Pirapora (MG) e São Carlos (SP) para a Zona Bioclimática 4; Garanhuns (PE), Vitória da Conquista (BA) e Campos (RJ) para a Zona Bioclimática 5; Jataí (GO), Bom Jesus da Lapa (BA) e João Pinheiro (MG) para a Zona Bioclimática 6; Bom Jesus do Piauí (PI), Cabrobó (PE) e Cuiabá (MT) para a Zona Bioclimática 7; e Manaus (AM), Pão de Açúcar (AL) e Rio de Janeiro (RJ) para a Zona Bioclimática 8.

As cidades foram selecionadas de acordo a disponibilidade de arquivo climático que pudesse ser utilizado nas simulações e também de forma a contemplar boa parte do território brasileiro.

\section{Planejamento do experimento fatorial}

Entre as diversas técnicas de análise de sensibilidade, a análise fatorial é a única que permite descobrir interações entre as variáveis (MONTGOMERY; RUNGER; HUBELE, 2012).

$\mathrm{O}$ primeiro passo do planejamento fatorial consiste na definição das variáveis a serem avaliadas. Com base na revisão bibliográfica e na análise das variáveis abordadas nas prescrições normativas em vigor no Brasil, foram consideradas as variáveis transmitância térmica, capacidade térmica e absortância solar das paredes externas e cobertura, além da existência de sombreamento, ventilação natural no ambiente em estudo e ático ventilado. $\mathrm{O}$ sombreamento e a ventilação natural foram considerados por serem estratégias complementares que podem afetar as variáveis termofísicas consideradas no estudo.

Foram estruturados dois experimentos fatoriais: um para as paredes externas e outro para a cobertura. 
Figura 1 - Planta baixa da edificação em estudo

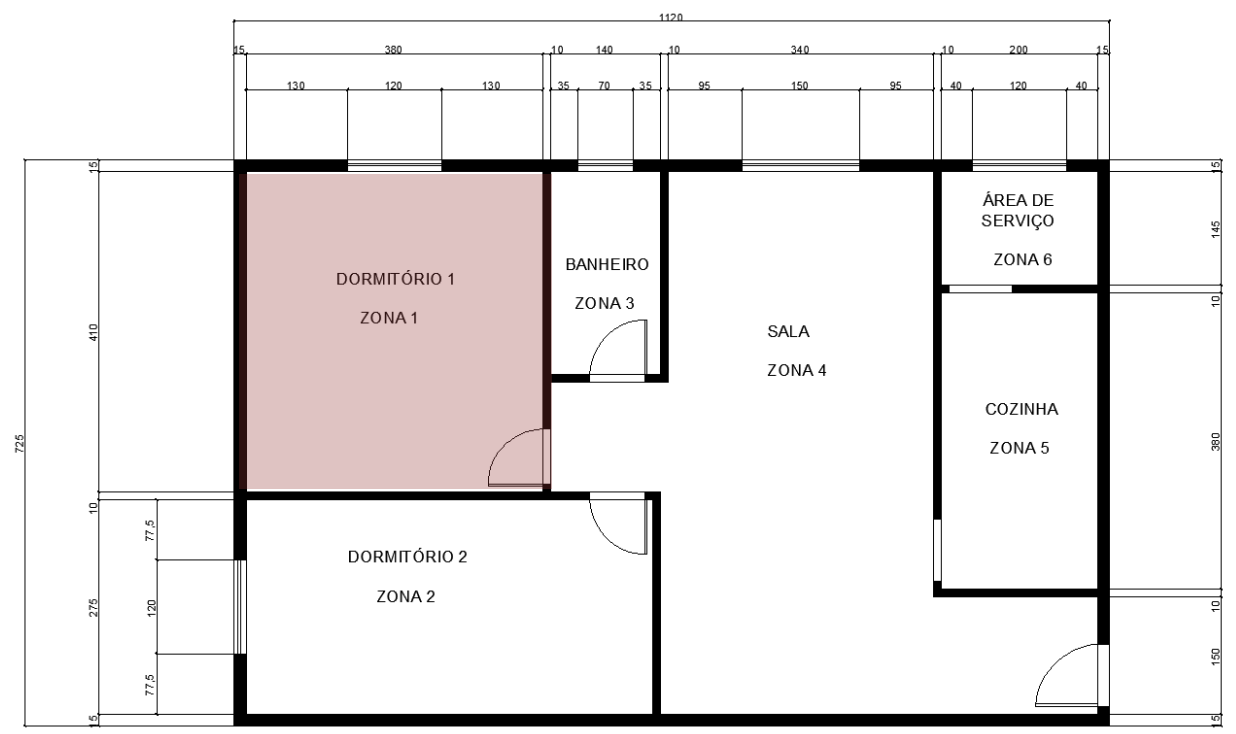

Os parâmetros em análise irão variar em níveis a partir de valores predeterminados, que, combinados entre si, irão resultar em conjuntos paramétricos de valores ordenados, conforme o planejamento fatorial. Aos fatores escolhidos atribuiu-se um nível dito baixo (-) e outro alto (+). É relevante ressaltar que um dos níveis produzirá um desempenho térmico superior, o que não significa necessariamente corresponder ao nível alto.

Para a definição dos níveis dos fatores da transmitância térmica e da capacidade térmica das paredes e coberturas, foram eleitos os valoreslimite propostos por Mahoney (KOENIGSBERGER; MAHONEY; EVANS, 1970) para a classificação das superfícies em leves ou pesadas e em isolantes e não isolantes (Tabela 2). Essa decisão baseou-se no estudo realizado por Ferreira, Souza e Assis (2015), que observaram que as recomendações das envoltórias segundo Mahoney apresentaram-se, em geral, mais apropriadas em relação às recomendações propostas pelas normas NBR 15220 e NBR 15575.

Para a transmitância, seja das paredes ou da cobertura, consideraram-se como nível alto do fator as superfícies isolantes. Para o atraso térmico e a absortância solar, os níveis altos foram considerados aqueles de maior valor numérico.

Para a determinação dos níveis da absortância solar seguiu-se a recomendação da norma NBR 15575 (ABNT, 2013), de que, caso a cor das paredes não esteja definida no projeto, simular para três alternativas de cor: cor clara $(\alpha=0,3)$, cor média $(\alpha=0,5)$ e cor escura $(\alpha=0,7)$. Foram assim adotados os valores extremos de 0,3 para superfícies claras e de 0,7 para superfícies escuras.

Para a análise do sombreamento o elemento de sombreamento utilizado foi a veneziana, o mais utilizado nas edificações residenciais e o recomendado pela NBR 15575 (ABNT, 2013). A avaliação será em torno da existência ou não do dispositivo de proteção.

De forma equivalente, a ventilação natural dos ambientes e o ático ventilado são abordados diante do uso ou não de tais estratégias.

Os níveis adotados para cada fator estão resumidos na Tabela 3 para as paredes externas e na Tabela 4 para a cobertura.

Para cada um dos experimentos fatorial, seja para as paredes externas, seja para a cobertura, há um caso-base em que nenhuma das variáveis presentes se encontra com nível alto, que servirá como balizador em relação aos efeitos dos fatores, sejam eles positivos ou negativos na variável de saída.

A influência de cada variável no processo é delimitada por meio de alterações controladas no processo e avaliação do impacto nos resultados obtidos nas interações.

Para validar os resultados obtidos é utilizada a análise estatística de variância por meio da ANOVA, verificando-se se as variações observadas são função das variações atribuídas ou devido a possíveis erros ocorridos durante os experimentos (MONTGOMERY; RUNGE; HUBELE, 2012). 
Tabela 2 - Recomendações de desempenho térmico da envoltória segundo Mahoney

\begin{tabular}{|c|c|c|c|}
\hline & $\begin{array}{c}\text { Transmitância } \\
\text { térmica - U }\left(W / m^{2} K\right)\end{array}$ & Fator solar - $\mathrm{FS}_{\mathbf{0}}(\%)$ & Atraso térmico - $\varphi(h)$ \\
\hline \multicolumn{4}{|c|}{ PAREDES } \\
\hline Leve & $\mathrm{U} \leq 2,80$ & $\mathrm{FS}_{\mathrm{o}} \leq 4,0$ & $\varphi \leq 3,0$ \\
\hline Pesada & $\mathrm{U} \leq 2,00$ & $\mathrm{FS}_{\mathrm{o}} \leq 4,0$ & $\varphi \geq 8,0$ \\
\hline \multicolumn{4}{|c|}{ COBERTURAS } \\
\hline Leve & $\mathrm{U} \leq 1,10$ & $\mathrm{FS}_{\mathrm{o}} \leq 4,0$ & $\varphi \leq 3,0$ \\
\hline Leve e bem isolada & $\mathrm{U} \leq 0,85$ & $\mathrm{FS}_{\mathrm{o}} \leq 3,0$ & $\varphi \leq 3,0$ \\
\hline Pesada & $\mathrm{U} \leq 0,85$ & $\mathrm{FS}_{\mathrm{o}} \leq 3,0$ & $\varphi \geq 8,0$ \\
\hline
\end{tabular}

Fonte: Koenigsberger, Mahoney e Evans (1970).

Tabela 3 - Níveis para o experimento fatorial para as paredes

\begin{tabular}{c|c|c|c|c|c|c}
\hline Fator & FATOR A & FATOR B & FATOR C & FATOR D & FATOR E & FATOR F \\
\hline Nível & $\begin{array}{c}\text { Transmitância } \\
\text { da parede } \\
\left(\mathbf{U}_{\mathbf{P A R}}\right) \\
{\left[\mathrm{W} /\left(\mathrm{m}^{2} \cdot \mathrm{K}\right)\right]}\end{array}$ & $\begin{array}{c}\text { Capacidade } \\
\text { térmica da } \\
\text { parede } \\
\left(\mathbf{C T}_{\mathbf{P A R}}\right) \\
{\left[\mathrm{J} /\left(\mathrm{m}^{2} \cdot \mathrm{K}\right)\right]}\end{array}$ & $\begin{array}{c}\text { Absortância } \\
\text { da parede } \\
\left(\boldsymbol{\alpha}_{\mathbf{P A R}}\right)\end{array}$ & $\begin{array}{c}\text { Transmitância } \\
\text { do vidro } \\
\left(\mathbf{U}_{\text {VID }}\right) \\
{\left[\mathrm{W} /\left(\mathrm{m}^{2} \cdot \mathrm{K}\right)\right]}\end{array}$ & $\begin{array}{c}\text { Sombreamento } \\
(\text { Somb })\end{array}$ & $\begin{array}{c}\text { Ventilação } \\
\left(\mathbf{F}_{\text {vent }}\right)\end{array}$ \\
\hline $\begin{array}{c}\text { Baixo }(-) \\
\text { Alto }(+)\end{array}$ & 2,97 & 159,00 & 0,3 & 5,7 & 0 & 0 \\
\hline
\end{tabular}

Tabela 4 - Níveis para o experimento fatorial para a cobertura

\begin{tabular}{c|c|c|c|c}
\hline Fator & FATOR A & FATOR B & FATOR C & FATOR D \\
\hline \multirow{2}{*}{ Nível } & $\begin{array}{c}\text { Transmitância da } \\
\text { cobertura }\left(\mathbf{U}_{\mathbf{C O B}}\right) \\
{\left[\mathrm{W} /\left(\mathrm{m}^{2} \cdot \mathrm{K}\right)\right]}\end{array}$ & $\begin{array}{c}\text { Capacidade térmica da } \\
\text { cobertura }\left(\mathbf{C T}_{\mathbf{C O B}}\right) \\
{\left[\mathrm{J} /\left(\mathrm{m}^{2} \cdot \mathrm{K}\right)\right]}\end{array}$ & $\begin{array}{c}\text { Absortância da } \\
\text { cobertura }\left(\boldsymbol{\alpha}_{\mathbf{C O B}}\right)\end{array}$ & $\begin{array}{c}\text { Ventilação do } \\
\text { ático }\left(\mathbf{F}_{\text {Ático }}\right)\end{array}$ \\
\hline Baixo $(-)$ & 1,94 & 37,0 & 0,3 & 0 \\
Alto $(+)$ & 0,85 & 233,0 & 0,7 & 1 \\
\hline
\end{tabular}

Os estudos de análise de sensibilidade têm demonstrado sua aplicabilidade para a análise de desempenho térmico de edificações, conforme trabalhos como de Tian (2013), Mara e Tarantola (2008), Saltelli, Tarantola e Campolongo (2000), Hyghet et al. (2012), Encinas e Herde (2013) e Silva e Ghisi (2013).

\section{Modelagem para a simulação}

\section{Geometria da edificação}

A edificação foi modelada conforme suas características geométricas (Figura 1). A unidade habitacional analisada foi uma das quatro que se encontram no último pavimento, de forma a possibilitar a análise dos efeitos da radiação na cobertura. A unidade habitacional foi dividida em seis zonas térmicas (dormitórios, zonas térmicas 1 e 2; banheiro, zona térmica 3; sala, zona térmica 4; cozinha, zona térmica 5; e área de serviço, zona térmica 6), conforme mostrado na Figura 2.
As unidades habitacionais do último pavimento foram modeladas como zonas térmicas similares às adotadas para a unidade habitacional em estudo. Não houve a separação por unidade habitacional nos demais pavimentos, para simplificação do modelo.

\section{Parâmetros de entrada das características termofísicas das envoltórias}

A escolha das envoltórias foi baseada em suas características termofísicas, conforme os valoreslimite propostos por Mahoney (KOENIGSBERGER; MAHONEY; EVANS, 1970) (Tabela 2), e nos níveis do experimento fatorial para cada uma das variáveis. As envoltórias utilizadas são encontradas no mercado e têm sua composição descrita na Tabela 5, assim como as características dos materiais que as compõem estão apresentadas na Tabela 6. As propriedades termofísicas dos materiais que compõem as envoltórias foram especificadas 
conforme a norma NBR 15220 (ABNT, 2005), Ordenes et al. (2003) e Morishita et al. (2013).

A resistência térmica considerada para a câmara de ar da parede foi de $0,16 \mathrm{~m}^{2} \mathrm{~K} / \mathrm{W}$, para superfícies de alta emissividade com espessura de $2,0 \mathrm{~cm}$ a 5,0 $\mathrm{cm}$. Já para a cobertura a resistência térmica considerada da câmara de ar com superfícies de alta emissividade com espessura de $6,0 \mathrm{~cm}$ com fluxo descendente foi de $0,21 \mathrm{~m}^{2} \mathrm{~K} / \mathrm{W}$ (ABNT, 2005).

O dispositivo modelado para sombreamento das aberturas foi uma veneziana horizontal, com refletância de 0,5 . Nos testes com sombreamento foi considerada a presença do sombreamento durante todo o dia.

Figura 2 - Modelo tridimensional da edificação com a localização das zonas térmicas em análise

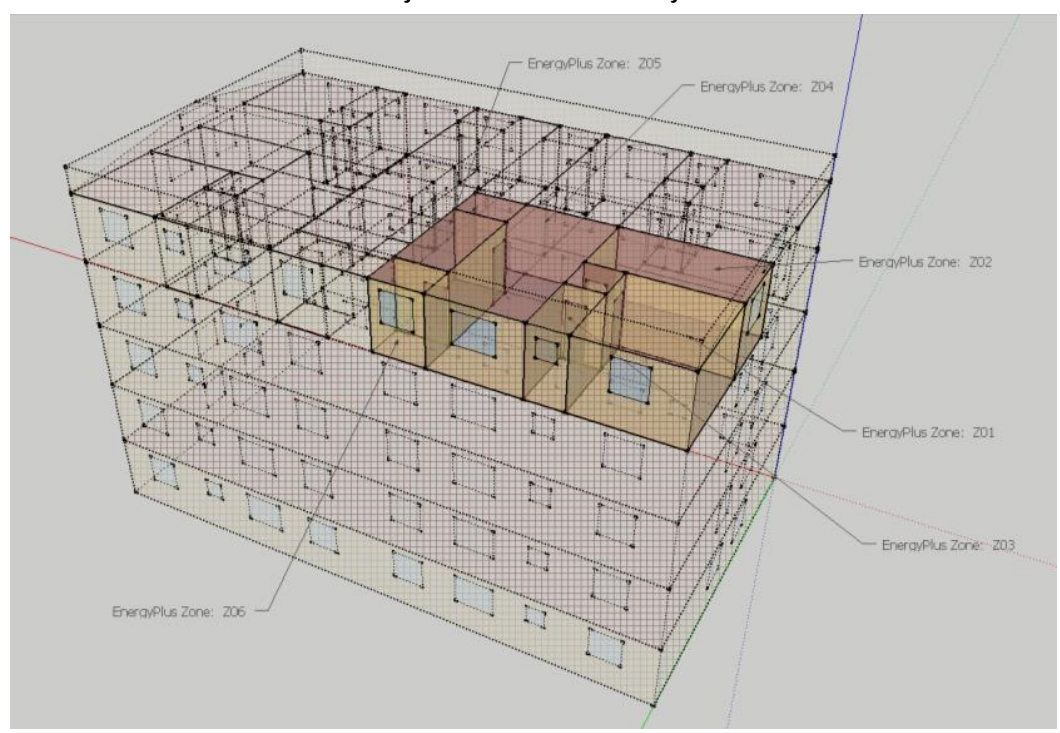

Tabela 5 - Envoltórias utilizadas no estudo e suas respectivas propriedades termofísicas

\begin{tabular}{|c|c|c|c|}
\hline Envoltória & $\begin{array}{c}\mathbf{U} \\
\left(\mathbf{W} / \mathbf{m}^{2} \mathbf{K}\right) \\
\end{array}$ & $\begin{array}{c}\mathrm{CT} \\
\left(\mathrm{kJ} / \mathrm{m}^{2} \mathbf{K}\right) \\
\end{array}$ & $\varphi(h)$ \\
\hline $\begin{array}{l}\text { Parede base } \\
\text { Argamassa externa }(2,5 \mathrm{~cm}) \text {, bloco de concreto }(9,0 \mathrm{~cm}) \text {, gesso }(0,2 \\
\mathrm{cm})\end{array}$ & 2,97 & 159,0 & 2,99 \\
\hline $\begin{array}{l}\text { Parede isolante } \\
\text { Argamassa }(2,5 \mathrm{~cm}), \text { bloco cerâmico }(14,0 \mathrm{~cm}) \text {, gesso }(0,2 \mathrm{~cm})\end{array}$ & 1,85 & 105,0 & 2,97 \\
\hline $\begin{array}{l}\text { Parede pesada } \\
\text { Adobe }(22,0 \mathrm{~cm})\end{array}$ & 2,80 & 331,5 & 8,00 \\
\hline $\begin{array}{l}\text { Parede isolante e pesada } \\
\text { Argamassa }(2,5 \mathrm{~cm}) \text {, bloco de concreto }(14,0 \mathrm{~cm}), \text { câmara de ar }(2,0 \text { a } \\
5,0 \mathrm{~cm}), \text { bloco de concreto }(14,0 \mathrm{~cm}), \text { argamassa }(2,5 \mathrm{~cm})\end{array}$ & 1,43 & 439,0 & 9,43 \\
\hline $\begin{array}{l}\text { Cobertura base } \\
\text { Telha cerâmica, câmara de ar }(>5,0 \mathrm{~cm}) \text {, forro de gesso }(3,0 \mathrm{~cm})\end{array}$ & 1,94 & 37,0 & 1,50 \\
\hline $\begin{array}{l}\text { Cobertura isolante } \\
\text { Telha cerâmica, câmara de ar }(>5,0 \mathrm{~cm}) \text {, espuma rígida de poliuretano } \\
(2,0 \mathrm{~cm}) \text {, forro de pvc }(1,0 \mathrm{~cm})\end{array}$ & 0,85 & 31,8 & 2,37 \\
\hline $\begin{array}{l}\text { Cobertura pesada } \\
\text { Telha de fibrocimento, câmara de ar }(>5,0 \mathrm{~cm}) \text {, laje maciça }(10,0 \mathrm{~cm})\end{array}$ & 2,06 & 233,0 & 5,00 \\
\hline $\begin{array}{l}\text { Cobertura isolante e pesada } \\
\text { Telha metálica }(0,1 \mathrm{~cm}) \text {, poliuretano }(4,0 \mathrm{~cm}), \text { telha metálica }(0,1 \mathrm{~cm}) \text {, } \\
\text { câmara de ar }(>5,0 \mathrm{~cm}) \text {, laje pré-moldada }(12,0 \mathrm{~cm})\end{array}$ & 0,53 & 176,0 & 11,20 \\
\hline
\end{tabular}


Tabela 6 - Características dos materiais utilizados na simulação computacional

\begin{tabular}{l|c|c|c|c}
\hline \multicolumn{1}{c|}{ Material } & $\begin{array}{c}\text { Espessura } \\
\text { equivalente } \\
{[\mathbf{m}]}\end{array}$ & $\begin{array}{c}\text { Condutividade } \\
\text { térmica } \\
{[\mathbf{W} / \mathbf{m} . \mathbf{K}]}\end{array}$ & $\begin{array}{c}\text { Censidade } \\
{\left[\mathbf{k g} / \mathbf{m}^{3}\right]}\end{array}$ & $\begin{array}{c}\text { Calor } \\
\text { específico } \\
{[\mathbf{J} / \mathbf{k g . K}]}\end{array}$ \\
\hline Argamassa reboco & 0,025 & 1,15 & 2.000 & 1.000 \\
Bloco de concreto $(9,0 \mathrm{~cm})$ & 0,025 & 1,75 & 105 & 1.000 \\
Bloco de concreto $(14,0 \mathrm{~cm})$ & 0,026 & 1,75 & 91 & 1.000 \\
Bloco cerâmico 6 furos quadrado $(14,0 \mathrm{~cm})$ & 0,014 & 0,90 & 2.290 & 920 \\
Adobe & 0,220 & 1,15 & 1.800 & 837 \\
Gesso & 0,002 & 0,70 & 1.200 & 840 \\
Concreto maciço & 0,100 & 1,75 & 2.200 & 1.000 \\
Laje pré-moldada & 0,095 & 1,05 & 1087 & 920 \\
Telha cerâmica & 0,010 & 1,05 & 2.000 & 920 \\
Telha de alumínio & 0,001 & 230,00 & 2.700 & 880 \\
Telha de fibrocimento & 0,003 & 0,95 & 1.900 & 840 \\
Forro de gesso & 0,030 & 0,70 & 1.200 & 840 \\
PVC & 0,010 & 0,20 & 1.300 & 960 \\
EPS & 0,020 & 0,04 & 16 & 1.420 \\
\hline
\end{tabular}

\section{Parâmetros de entrada de cargas internas}

É sabido que as cargas internas irão influenciar o desempenho térmico das edificações, contudo, para a presente avaliação, de forma a isolar o efeito da envoltória e reduzir o número de testes fatoriais a serem realizados, uma vez que, introduzindo as variáveis das cargas internas, esse número aumentaria consideravelmente. Assim, não foi considerada qualquer carga interna, seja ela de equipamentos, iluminação ou pessoas.

\section{Parâmetros de entrada da ventilação natural}

Para uma avaliação mais precisa do impacto da ventilação no desempenho térmico da edificação, optou-se por simular a ventilação natural no módulo "Airflow Network" do EnergyPlus. Os coeficientes de pressão foram calculados pelo programa. Os coeficientes de descarga adotados foram de 0,65 para as portas e de 0,6 para as janelas, conforme manual do próprio programa.

A princípio não foi considerado nenhum tipo de controle para o uso das aberturas nas simulações do experimento fatorial com o intuito de avaliar o impacto dessa variável tanto no desconforto por calor quanto por frio. Quando a ventilação natural era um parâmetro ativo na avaliação, as janelas e portas eram consideradas abertas durante as 24 horas do dia. Apenas a porta de entrada é exceção, considerada sempre fechada. Os controles da ventilação foram inseridos posteriormente, somente na simulação para a verificação das recomendações, podendo ser usado ou não o controle por temperatura associado à temperatura de conforto local.
Para a ventilação do ático foram modeladas aberturas com dimensões de 2,20x0,5 m nos oitões, conforme observado no mercado.

\section{Arquivos climáticos}

Uma das limitações encontradas no trabalho refere-se à disponibilidade de um número inexpressivo de arquivos climáticos para o Brasil. Encontram-se disponíveis 27 arquivos climáticos TRY ${ }^{1}$. Para suprir essa limitação, de forma complementar, adotaram-se também os arquivos climáticos desenvolvidos por Roriz (2012), elaborados a partir de dados meteorológicos do Instituto Nacional de Meteorologia (Inmet) dos anos de 2000 a 2010 (INSTITUTO..., 2013).

\section{Parâmetros de saída}

As variáveis de saída solicitadas pelo software de simulação foram a temperatura externa do ar horária, a temperatura neutra ou de conforto horária, a temperatura operativa interna horária das zonas térmicas e a temperatura do ar interno horária das zonas térmicas, todas em graus Celsius.

As temperaturas de conforto serão utilizadas para o cálculo da faixa de conforto, e as temperaturas operativas para a verificação da condição de conforto ou não.

\section{Definição das horas de conforto}

Para a quantificação das horas de conforto o modelo adotado foi o desenvolvido por de Dear e Brager (2002), adotado pela norma ASHRAE 55

${ }^{1}$ Os arquivos climáticos do tipo Teste Reference Year (TRY) são arquivos constituídos com 1 ano de dados médios, sem extremos de temperatura. 
(AMERICAN..., 2013). A faixa de conforto utilizada foi a de $\pm 3,5{ }^{\circ} \mathrm{C}$, de acordo com a recomendação da norma ASHRAE 55 (AMERICAN..., 2013).

Se as temperaturas operativas se apresentassem dentro da faixa, seriam contabilizadas como horas de conforto, caso contrário, como horas de desconforto. As condições simuladas com maior número de horas de conforto foram consideradas como as recomendações de projeto para cada uma das localidades analisadas.

\section{Resultados}

\section{Variáveis de maior influência segundo a análise fatorial}

$\mathrm{O}$ experimento fatorial permitiu identificar aquelas variáveis com maior influência no desempenho térmico da edificação para os diferentes climas em análise. A influência das variáveis pode ser tanto positiva, de forma a aumentar as horas de conforto, como negativa, reduzindo as horas de conforto. A influência de cada variável em análise para cada uma das cidades é apresentada na Tabela 7.

Não foi observado um padrão único em nenhuma das zonas bioclimáticas em relação às variáveis de maior influência para cada localidade, mas sim algumas semelhanças. De forma geral, para as paredes as variáveis com maior influência foram a capacidade térmica, a absortância solar e a ventilação natural dos ambientes. Já para as coberturas as principais variáveis foram a transmitância térmica e a absortância solar.

Mediante a indicação das variáveis com maior influência no desempenho térmico para cada localidade foram realizadas simulações para a obtenção das melhores condições de conforto, apresentadas a seguir.

\section{Condição de melhor desempenho térmico}

Para avaliar os desempenhos das envoltórias foram analisados os percentuais de horas de conforto obtidos a partir das simulações realizadas com base na estrutura do experimento fatorial. A condição com maior número de horas de conforto foi adotada como recomendação de projeto para a localidade. As recomendações são apresentadas na Tabela 8, e aquelas mandatórias para o bom desempenho da edificação foram preenchidas com cinza escuro, enquanto as recomendações opcionais, que apenas auxiliam na melhoria do desempenho térmico, foram preenchidas com cinza claro. As recomendações deixadas em branco não se aplicam para aquela localidade. Já as recomendações preenchidas com hachura, são também obrigatórias, mas com aplicações sazonais (apenas nos períodos quentes).

Tabela 7 - Influência das variáveis (\%) para cada um dos climas analisados segundo o experimento fatorial

\begin{tabular}{|c|c|c|c|c|c|c|c|c|c|c|c|c|}
\hline ZB & \multicolumn{3}{|c|}{ ZB1 } & \multicolumn{3}{|c|}{ ZB2 } & \multicolumn{3}{|c|}{ ZB3 } & \multicolumn{3}{|c|}{ ZB4 } \\
\hline Variáveis & $\begin{array}{c}\text { Campos } \\
\text { do Jordão }\end{array}$ & Maringá & $\begin{array}{c}\text { São } \\
\text { Joaquim }\end{array}$ & Florestal & $\begin{array}{c}\text { Santa } \\
\text { Maria }\end{array}$ & $\begin{array}{c}\text { Teresópoli } \\
s\end{array}$ & $\begin{array}{c}\text { Belo } \\
\text { Horizonte }\end{array}$ & $\begin{array}{c}\text { Florianóp } \\
\text { olis }\end{array}$ & $\begin{array}{l}\text { Ponta } \\
\text { Porã }\end{array}$ & Brasília & Pirapora & São Carlos \\
\hline $\mathbf{U}_{\mathrm{PAR}}$ & 6,89 & 0,01 & 6,78 & 0,25 & 2,65 & 0,07 & 0,08 & 1,49 & 0,03 & 0,42 & 0,13 & 0,02 \\
\hline $\mathbf{C T}_{\mathrm{PAR}}$ & 20,07 & 4,04 & 16,89 & 34,26 & 15,22 & 3,86 & 1,67 & 21,66 & 5,17 & 19,43 & 2,09 & 11,55 \\
\hline$\alpha_{\mathrm{PAR}}$ & 25,27 & 33,02 & 22,34 & 0,05 & 1,87 & 39,40 & 18,95 & 0,49 & 32,11 & 13,13 & 38,92 & 18,11 \\
\hline $\mathbf{U}_{\mathrm{VID}}$ & 7,06 & 11,32 & 10,53 & 0,43 & 1,93 & 6,54 & 5,21 & 0,44 & 3,40 & 4,75 & 5,91 & 4,36 \\
\hline Somb & 0,76 & 2,04 & 0,03 & 0,18 & 17,36 & 0,00 & 1,11 & 5,35 & 0,31 & 2,68 & 0,16 & 0,00 \\
\hline $\mathbf{F}_{\text {VENT }}$ & 12,74 & 5,56 & 14,96 & 29,23 & 6,40 & 33,54 & 15,02 & 12,53 & 8,46 & 0,94 & 18,69 & 51,22 \\
\hline $\mathbf{U}_{\mathrm{COB}}$ & 5,79 & 26,00 & 10,04 & 0,32 & 17,72 & 1,37 & 11,52 & 1,18 & 16,81 & 0,69 & 5,04 & 1,89 \\
\hline $\mathrm{CT}_{\mathrm{COB}}$ & 0,30 & 5,20 & 0,88 & 0,00 & 3,66 & 0,06 & 4,87 & 0,81 & 7,34 & 7,25 & 3,22 & 1,73 \\
\hline$\alpha_{\mathrm{COB}}$ & 50,47 & 0,58 & 42,40 & 52,19 & 0,05 & 44,91 & 4,31 & 7,78 & 14,53 & 6,77 & 0,00 & 20,73 \\
\hline $\mathbf{F}_{\text {ATICO }}$ & 1,45 & 0,08 & 1,56 & 0,44 & 2,08 & 0,06 & 0,92 & 1,89 & 3,77 & 4,50 & 0,00 & 0,00 \\
\hline ZB & \multicolumn{3}{|c|}{ ZB5 } & \multicolumn{3}{|c|}{ ZB6 } & \multicolumn{3}{|c|}{ ZB7 } & \multicolumn{3}{|c|}{ ZB8 } \\
\hline Variáve is & $\begin{array}{c}\text { Garanhun } \\
s\end{array}$ & $\begin{array}{l}\text { Vitória da } \\
\text { Conquista }\end{array}$ & Campos & Jataí & $\begin{array}{c}\text { Bom Jesus } \\
\text { da Lapa }\end{array}$ & $\begin{array}{c}\text { João } \\
\text { Pinheiro }\end{array}$ & $\begin{array}{c}\text { Bom Jesus } \\
\text { do Piauí }\end{array}$ & Cabrobó & Cuiabá & Manaus & $\begin{array}{l}\text { Pão de } \\
\text { Açúcar }\end{array}$ & $\begin{array}{l}\text { Rio de } \\
\text { Janeiro }\end{array}$ \\
\hline $\mathbf{U}_{\mathbf{P A R}}$ & 6,52 & 0,07 & 0,14 & 2,46 & 0,21 & 0,27 & 0,37 & 2,43 & 0,70 & 0,95 & 1,71 & 0,33 \\
\hline $\mathbf{C T}_{\mathrm{PAR}}$ & 50,79 & 3,86 & 4,89 & 40,93 & 0,51 & 29,37 & 1,76 & 12,70 & 10,36 & 7,95 & 16,69 & 1,10 \\
\hline $\boldsymbol{\alpha}_{\mathrm{PAR}}$ & 2,62 & 39,40 & 26,70 & 11,87 & 37,75 & 9,47 & 39,42 & 35,68 & 28,19 & 20,16 & 32,33 & 21,80 \\
\hline $\mathbf{U}_{\mathrm{VID}}$ & 5,48 & 6,54 & 6,12 & 3,85 & 2,32 & 0,71 & 13,26 & 10,59 & 9,25 & 5,85 & 9,36 & 7,17 \\
\hline Somb & 0,84 & 0,00 & 0,21 & 1,99 & 0,14 & 0,42 & 1,46 & 0,75 & 0,66 & 0,31 & 0,18 & 1,03 \\
\hline $\mathbf{F}_{\text {VENT }}$ & 13,06 & 33,54 & 20,73 & 5,32 & 18,88 & 10,29 & 4,69 & 12,17 & 34,11 & 51,53 & 18,43 & 42,64 \\
\hline $\mathbf{U}_{\mathrm{COB}}$ & 0,46 & 0,80 & 2,86 & 22,91 & 0,01 & 0,07 & 8,86 & 13,22 & 15,01 & 14,24 & 11,62 & 20,86 \\
\hline $\mathbf{C T}_{\mathrm{COB}}$ & 0,38 & 0,75 & 1,31 & 11,75 & 0,00 & 0,04 & 0,99 & 0,79 & 0,50 & 0,09 & 0,03 & 1,64 \\
\hline $\boldsymbol{\alpha}_{\mathrm{COB}}$ & 17,03 & 24,58 & 4,15 & 28,75 & 8,55 & 38,42 & 31,35 & 56,20 & 45,59 & 54,67 & 46,40 & 11,84 \\
\hline $\mathbf{F}_{\text {ATICO }}$ & 1,89 & 1,96 & 1,00 & 1,50 & 0,01 & 2,87 & 0,20 & 3,07 & 1,14 & 1,61 & 1,77 & 0,36 \\
\hline
\end{tabular}


Tabela 8 - Resumo das recomendações obtidas por simulações para cada uma das cidades analisadas por zona bioclimática

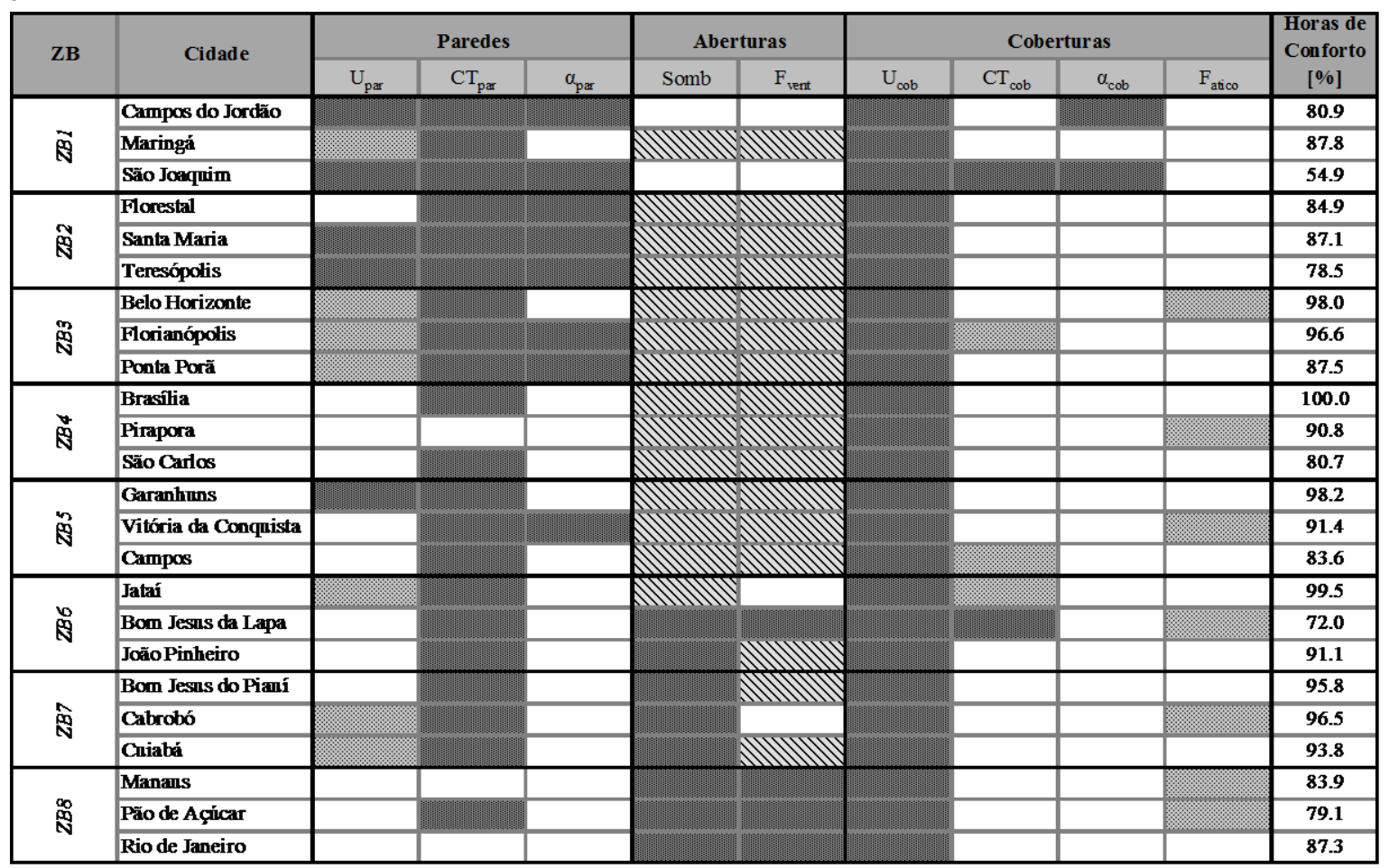

Nota: Legenda:

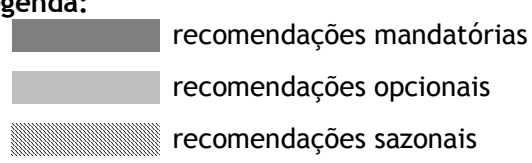

Para as cidades pertencentes à Zona Bioclimática 1, Campos do Jordão, Maringá e São Joaquim, percebe-se que os climas de Campos do Jordão e São Joaquim apresentam maior rigor por frio. Para estes climas a absortância alta da envoltória $(\alpha \geq 0,7)$ resulta em melhores condições de conforto. Já para a cidade de Maringá, com menor rigor térmico por frio, há recomendações da envoltória com absortância solar baixa $(\alpha \leq 0,3)$, sombreamento das aberturas e ventilação dos ambientes nos períodos quentes. As recomendações comuns às três cidades são coberturas isolantes $\left(\mathrm{U} \leq 0,85 \mathrm{~W} / \mathrm{m}^{2} \mathrm{~K}\right)$, paredes com grande atraso térmico e isolantes $(\varphi \geq 8,00 \mathrm{~h}$ e $\left.\mathrm{U} \leq 2,00 \mathrm{~W} / \mathrm{m}^{2} \mathrm{~K}\right)$, sendo esta última recomendação opcional para a cidade de Maringá, uma vez que contribui de forma restrita para a melhoria do desempenho térmico.

Para as cidades selecionadas para a Zona Bioclimática 2 (Florestal, Santa Maria e Teresópolis), as recomendações foram equivalentes: paredes pesadas $(\varphi \geq 8,00 \mathrm{~h})$ e escuras $(\alpha \geq 0,7)$; aberturas com sombreamento para os períodos quentes apenas; ventilação natural para os períodos quentes; e cobertura isolante ( $U \leq 0,85$ $\left.\mathrm{W} / \mathrm{m}^{2} \mathrm{~K}\right)$. Para as cidades de Santa Maria e
Teresópolis as paredes devem ser também isolantes $\left(\mathrm{U} \leq 2,00 \mathrm{~W} / \mathrm{m}^{2} \mathrm{~K}\right)$.

As recomendações para as três cidades da Zona Bioclimática 3 (Belo Horizonte, Florianópolis e Ponta Porã) foram por paredes externas pesadas $(\varphi \geq 8,00 \mathrm{~h}) ;$ se isolantes $\left(\mathrm{U} \leq 2,00 \mathrm{~W} / \mathrm{m}^{2} \mathrm{~K}\right)$, auxiliam a obter melhores condições de conforto. Para as cidades de Florianópolis e Ponta Porã as paredes externas devem ter absortância igual ou superior a 0,7, enquanto para Belo Horizonte esse valor não deve ser superior a 0,3 . O uso de paredes isolantes, pesadas e claras para a cidade de Florianópolis resultou em $79,5 \%$ de horas de conforto, enquanto as paredes com essas mesmas características, mas escuras, resultaram em 96,6\% de horas de conforto. De forma similar, para a cidade de Ponta Porã o uso de paredes escuras ao invés de claras resultou em um aumento de 78,6\% para $87,5 \%$ das horas de conforto. O comportamento das temperaturas operativas pode ser observado na Figura 3, que demonstra haver redução das horas de desconforto por frio superior ao aumento das horas de conforto por calor. $\mathrm{O}$ sombreamento das aberturas e a ventilação devem ser sazonais (períodos quentes apenas), e a cobertura deve ser isolante $\left(\mathrm{U} \leq 0,85 \mathrm{~W} / \mathrm{m}^{2} \mathrm{~K}\right)$. As 
recomendações particulares observadas foram a ventilação no ático para Belo Horizonte e cobertura pesada $(\varphi \geq 8,00 \mathrm{~h})$ para Florianópolis.

Para a Zona Bioclimática 4 foram observadas diferenças nas recomendações das paredes externas para as cidades (Brasília, Pirapora e São Carlos). Para Brasília e São Carlos as paredes devem ser pesadas $(\varphi \geq 8,00 \mathrm{~h})$ e claras $(\alpha \leq 0,3)$. Já para a cidade de Pirapora as paredes devem ser não isolantes $(\mathrm{U} \geq 2,80 \mathrm{~W} / \mathrm{m} 2 \mathrm{~K}$, assim como para Brasília e São Carlos), leves $(\varphi \leq 3,0$ h) e claras $(\alpha \leq 0,3$, assim como para Brasília). Quanto às demais recomendações, para as três cidades as aberturas devem ser sombreadas e permitir a ventilação natural nos períodos quentes. As coberturas devem ser isolantes $\left(\mathrm{U} \leq 2,00 \mathrm{~W} / \mathrm{m}^{2} \mathrm{~K}\right)$, sendo que para Pirapora o ático ventilado contribui para a melhoria do desempenho térmico.
Para as cidades de Garanhuns, Vitória da Conquista e Campos, pertencentes à Zona Bioclimática 5, as paredes externas devem ser pesadas $(\varphi \geq 8,00 \mathrm{~h})$; as aberturas devem ser sombreadas e permitir a ventilação natural nos períodos quentes; e as coberturas devem ser isolantes $\left(\mathrm{U} \leq 0,85 \mathrm{~W} / \mathrm{m}^{2} \mathrm{~K}\right)$. Para a cidade de Garanhuns, além de pesadas, as paredes devem ser também isolantes $\left(\mathrm{U} \leq 2,00 \mathrm{~W} / \mathrm{m}^{2} \mathrm{~K}\right)$ e claras $(\alpha \leq 0,3)$. Para Vitória da Conquista as paredes escuras representaram melhoria no desempenho térmico (aumento das horas de conforto de 78,1\% para 91,4\%) conforme é apresentado na Figura 4, assim como o ático ventilado. Para a cidade de Campos, se a cobertura for pesada $(\varphi \geq 8,00 \mathrm{~h})$, há contribuição para o desempenho térmico.

Figura 3 - Gráfico da variação da temperatura operativa ao longo do ano para as paredes claras e escuras

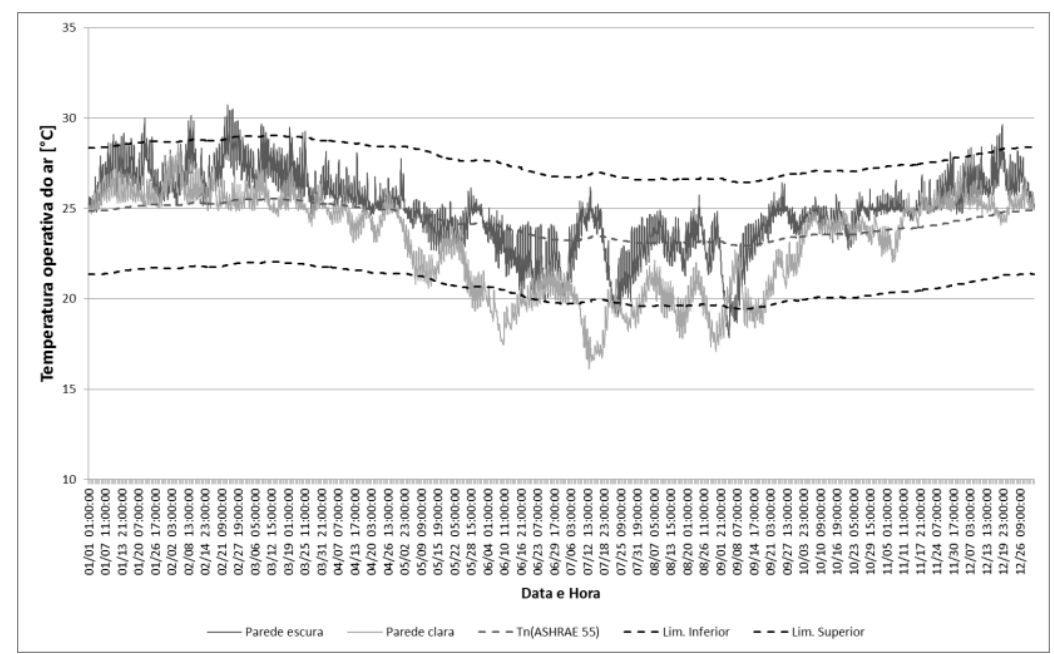

(a) Florianópolis

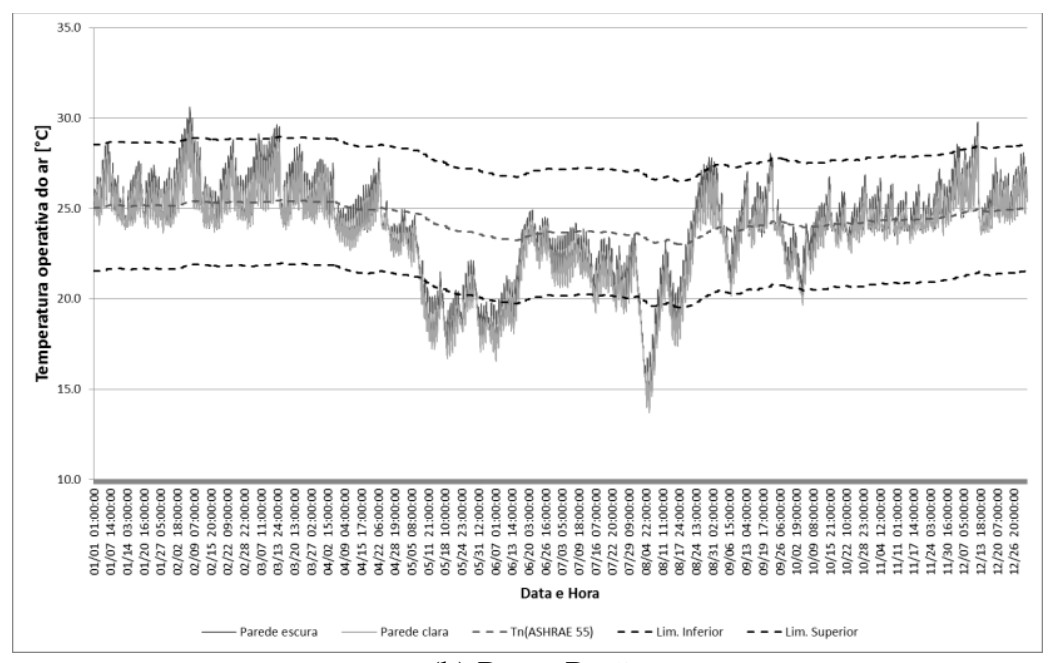

(b) Ponta Porã 
Figura 4 - Gráfico da variação da temperatura operativa ao longo do ano para as paredes claras e escuras para a cidade de Vitória da Conquista

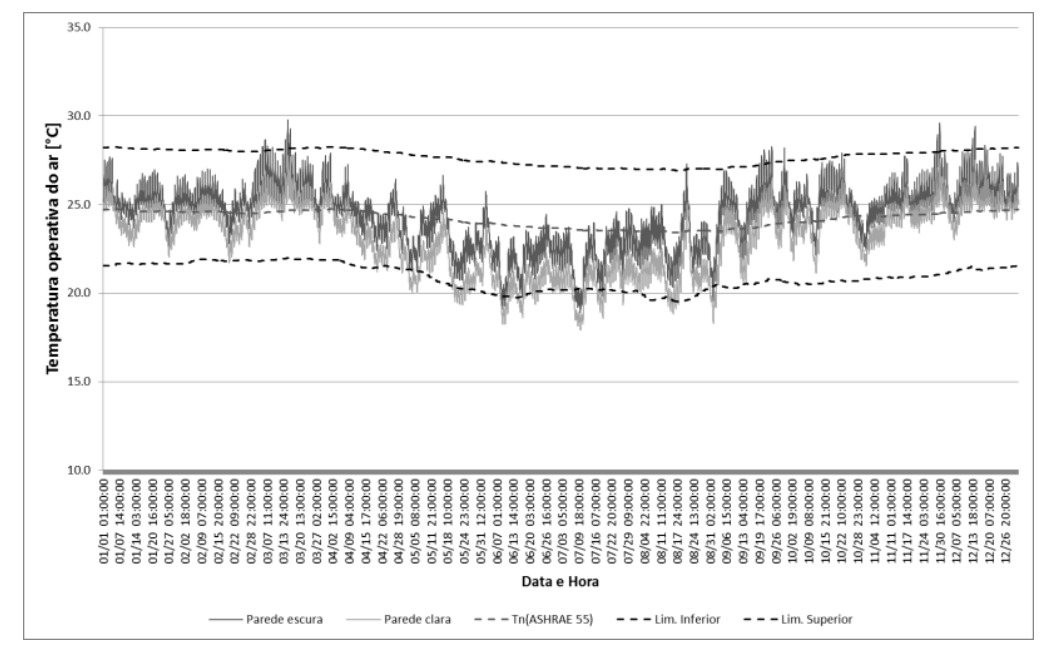

Nas cidades da Zona Bioclimática 6 (Jataí, Bom Jesus da Lapa e João Pinheiro) as recomendações foram por paredes pesadas $(\varphi \geq 8,00 \mathrm{~h})$ e claras $(\alpha \leq 0,3)$; sombreamento das aberturas (para Bom Jesus e João Pinheiro e opcional para Jataí); e coberturas isolantes $\left(\mathrm{U} \leq 0,85 \mathrm{~W} / \mathrm{m}^{2} \mathrm{~K}\right)$ e claras $(\alpha \leq 0,3)$. A ventilação dos ambientes beneficia apenas os climas de Bom Jesus da Lapa e João Pinheiro. Para o clima da cidade de Jataí as paredes isolantes $\left(\mathrm{U} \leq 2,00 \mathrm{~W} / \mathrm{m}^{2} \mathrm{~K}\right)$ e claras $(\alpha \leq 0,3)$ e coberturas pesadas $(\varphi \geq 8,00 \mathrm{~h})$ e claras $(\alpha \leq 0,3)$ contribuíram para a melhoria do desempenho térmico. No caso de Bom Jesus da Lapa as coberturas devem também ser pesadas $(\varphi \geq 8,00 \mathrm{~h}$ ), além de isolantes (como para as demais), e o ático ventilado promove melhorias nas condições de conforto.

Para a Zona Bioclimática 7 (Bom Jesus do Piauí, Cabrobó e Cuiabá) as paredes devem ser pesadas $(\varphi \geq 8,00$ h) e claras $(\alpha \leq 0,3) ;$ as aberturas sombreadas durante todo o ano; e as coberturas isolantes $\left(\mathrm{U} \leq 0,85 \mathrm{~W} / \mathrm{m}^{2} \mathrm{~K}\right)$ e claras $(\alpha \leq 0,3)$. Além dessas recomendações, para as cidades de Bom Jesus do Piauí e Cuiabá a ventilação seletiva deve ser permitida, e para as cidades de Cabrobó e Cuiabá as paredes isolantes $\left(\mathrm{U} \leq 2,00 \mathrm{~W} / \mathrm{m}^{2} \mathrm{~K}\right)$ contribuem para o conforto.

E, por fim, para a Zona Bioclimática 8 (Manaus, Pão de Açúcar e Rio de Janeiro) as paredes devem ser não isolantes $\left(\mathrm{U} \geq 2,80 \mathrm{~W} / \mathrm{m}^{2} \mathrm{~K}\right)$ e claras $(\alpha \leq 0,3)$. As aberturas devem ser sombreadas e permitir a ventilação natural durante todo o ano. As coberturas devem ser isolantes ( $U \leq 0,85$ $\left.\mathrm{W} / \mathrm{m}^{2} \mathrm{~K}\right)$ e leves $(\varphi \leq 3,0)$. A principal diferença observada para as cidades dessa zona bioclimática refere-se ao atraso térmico das paredes externas. Enquanto para as cidades de Manaus e Rio de Janeiro, cidades de clima quente e úmido, as paredes devem ser leves $(\varphi \leq 3,0 \mathrm{~h})$, para Pão de Açúcar, de clima quente e seco, devem ser pesadas $(\varphi \geq 8,00 \mathrm{~h})$. Para as cidades do Rio de Janeiro e Pão de Açúcar a utilização de ático ventilado também contribui para a melhoria das condições de conforto.

Para as Zonas Bioclimáticas 6, 7 e 8 foi observado que as superfícies escuras $(\alpha \geq 0,7)$, sejam paredes ou coberturas, contribuem significativamente para a redução das horas de conforto para as localidades analisadas.

Os resultados obtidos se confirmaram para todas as orientações testadas.

\section{Comparação das recomendações obtidas por simulação com as recomendações normativas}

Segundo a norma NBR 15220 (ABNT, 2005), cidades pertencentes às Zonas Bioclimáticas 1 e 2 devem ter paredes leve e coberturas leves e isoladas. As recomendações obtidas por simulação apontam que as paredes externas, além de isolantes, devem ser também pesadas $(\varphi \geq 8,00 \mathrm{~h})$, sendo o valor máximo de atraso térmico de $4,3 \mathrm{~h}$ um valor inadequado, devendo as paredes externas ser limitadas por um valor mínimo de atraso térmico de $8 \mathrm{~h}$. Outro ponto para discussão é a limitação da absortância através do fator solar em um valor máximo, podendo limitar o valor da absortância em valores mais baixos, uma vez que as recomendações obtidas por simulação apontaram que valores mais altos de absortância solar $(\alpha \geq 0,7)$ contribuem para a melhoria das condições de conforto térmico. Além disso, o valor da transmitância de $3,00 \mathrm{~W} / \mathrm{m}^{2} \mathrm{~K}$ é um valor bastante permissivo. Quanto às coberturas, observa-se que a recomendação normativa e obtida 
nas simulações é por cobertura isolante, contudo novamente $\mathrm{o}$ valor de transmitância parece ser muito permissivo. Limitar os valores da capacidade térmica e da absortância para as coberturas nessa zona em valores baixos (cobertura leve e clara) pode prejudicar o desempenho térmico de edificações inseridas em climas com maior rigor térmico por frio, como o caso de São Joaquim.

Para as Zonas Bioclimáticas 1 e 2 a norma NBR 15575 (ABNT, 2013) recomenda que as paredes externas tenham transmitância térmica inferior a $2,50 \mathrm{~W} / \mathrm{m}^{2} \mathrm{~K}$ e capacidade térmica superior a 130 $\mathrm{kJ} / \mathrm{m}^{2} \mathrm{~K}$. Contudo, os resultados obtidos por simulação mostraram que os valores da capacidade térmica devem ser bem superiores ao valor de 130 $\mathrm{kJ} / \mathrm{m}^{2} \mathrm{~K}$, sendo indicados, de acordo com os resultados obtidos, valores iguais ou superiores a $330 \mathrm{~kJ} / \mathrm{m}^{2} \mathrm{~K}$. Além disso, é importante rever a absortância das paredes externas, que devem ser escuras. No que concerne às coberturas, o limite do valor da transmitância térmica de $2,30 \mathrm{~W} / \mathrm{m}^{2} \mathrm{~K}$ mostra-se bastante permissivo. Também para o caso das coberturas é importante limitar os valores da capacidade térmica e da absortância solar, de forma a garantir, neste caso, que estas sejam leves e claras respectivamente.

Para a Zona Bioclimática 3, o observado em relação às recomendações da norma NBR 15220 (2005) são paredes leves refletoras e cobertura leve isolada. Tal qual ocorreu para as Zonas Bioclimáticas 1 e 2, o questionamento envolve a limitação do atraso térmico e da absortância em um valor máximo, e não em um valor mínimo, para as paredes externas, o que permitiria melhores condições de conforto para as cidades, conforme apontaram os resultados das simulações. Além disso, o valor da transmitância térmica de 3,6 $\mathrm{W} / \mathrm{m} 2 \mathrm{~K}$ aparenta ser um valor elevado, devendo ser mais restritivo, com o intuito de garantir o isolamento das paredes externas. $\mathrm{O}$ mesmo se aplica para a transmitância das coberturas $(\mathrm{U} \leq 2,0$ $\left.\mathrm{W} / \mathrm{m}^{2} \mathrm{~K}\right)$.

Para esta zona, a norma NBR 15575 (2013) permite variação da transmitância térmica em função da absortância das paredes externas. $\mathrm{O}$ que se observou é que a absortância não deve ser limitada, mas para superfícies com absortância igual ou inferior a 0,6 o valor de $3,7 \mathrm{~W} / \mathrm{m}^{2} \mathrm{~K}$ é bastante permissivo, devendo ser reduzido mesmo para paredes claras. No caso das coberturas é importante que a absortância seja limitada em valores mais baixos e associada a valores de transmitância térmica mais restritivos. Também é importante estabelecer valores-limite para a capacidade térmica da cobertura, de forma a garantir que estas sejam leves.
No caso das Zonas Bioclimáticas 4 e 6 as recomendações da norma NBR 15220 para as paredes externas e coberturas mostraram-se adequadas, devendo apenas os valores da transmitância térmica da cobertura ser mais restritivos do que $2,0 \mathrm{~W} / \mathrm{m}^{2} \mathrm{~K}$. No que se refere às recomendações da norma NBR 15575, questionase a limitação da capacidade térmica das paredes em valores iguais ou superiores a $130 \mathrm{~kJ} / \mathrm{m}^{2} \mathrm{~K}$, quando pode haver a necessidade de valores bem superiores a este para a garantia de um bom desempenho térmico. Os resultados apontaram para um melhor desempenho de paredes com capacidade térmica igual ou superior a 330 $\mathrm{kJ} / \mathrm{m}^{2} \mathrm{~K}$. Como para a Zona Bioclimática 3, as recomendações para as coberturas devem garantir que estas sejam leves e claras, havendo também a necessidade de se restringir o valor da transmitância térmica.

Avaliando as recomendações normativas para a Zona Bioclimática 5, observa-se que tanto para a norma NBR 15220 como para a NBR 15575 as recomendações devem garantir que as paredes sejam pesadas, seja através do atraso térmico ou da capacidade térmica, estabelecendo um valor-limite inferior. Adicionalmente, as normas não devem restringir o valor da transmitância térmica e da absortância solar dessas superfícies, de forma a permitir a variação delas conforme a necessidade do clima local. As coberturas devem ser necessariamente isolantes e claras, o que aponta a necessidade de restrição da transmitância térmica e da absortância em valores inferiores.

Para a Zona Bioclimática 7 o questionamento envolve a recomendação da norma NBR 15220 de coberturas pesadas, quando na verdade as coberturas isolantes e leves apresentaram melhor desempenho térmico. Assim, os valores de atraso térmico deveriam ter um limite superior, e valores de transmitância térmica mais restritivos para as coberturas dessa zona. Além disso, é fundamental restringir a absortância das coberturas em cores claras. Essas mesmas observações são válidas para as recomendações da norma NBR 15575. Outro ponto referente às recomendações da NBR 15575 diz respeito à capacidade térmica das paredes, que devem possuir valor bem superior a $130 \mathrm{~kJ} / \mathrm{m}^{2} \mathrm{~K}$, conforme exposto anteriormente.

Por fim, analisando as recomendações da norma NBR 15220 para a Zona Bioclimática 8, percebese que as recomendações para as paredes apenas merecem atenção, uma vez que, em algumas localidades em que há o predomínio do clima quente e seco, pode haver a necessidade de que as paredes possuam atraso superior ao sugerido pela norma $(\varphi \leq 4,3$ h). Para essa zona, as recomendações da norma NBR 15575 deveriam 
limitar a absortância das paredes e coberturas, de forma a garantir que estas tenham valores baixos, assim como a capacidade térmica das coberturas em valores que garantam que as superfícies sejam leves.
A seguir são apresentados quadros-resumo (Quadro 1 e Quadro 2) comparativos entre os resultados obtidos com os valores-limite normativos.

Quadro 1 - Resumo comparativo entre os resultados obtidos e os valores normativos para as paredes externas

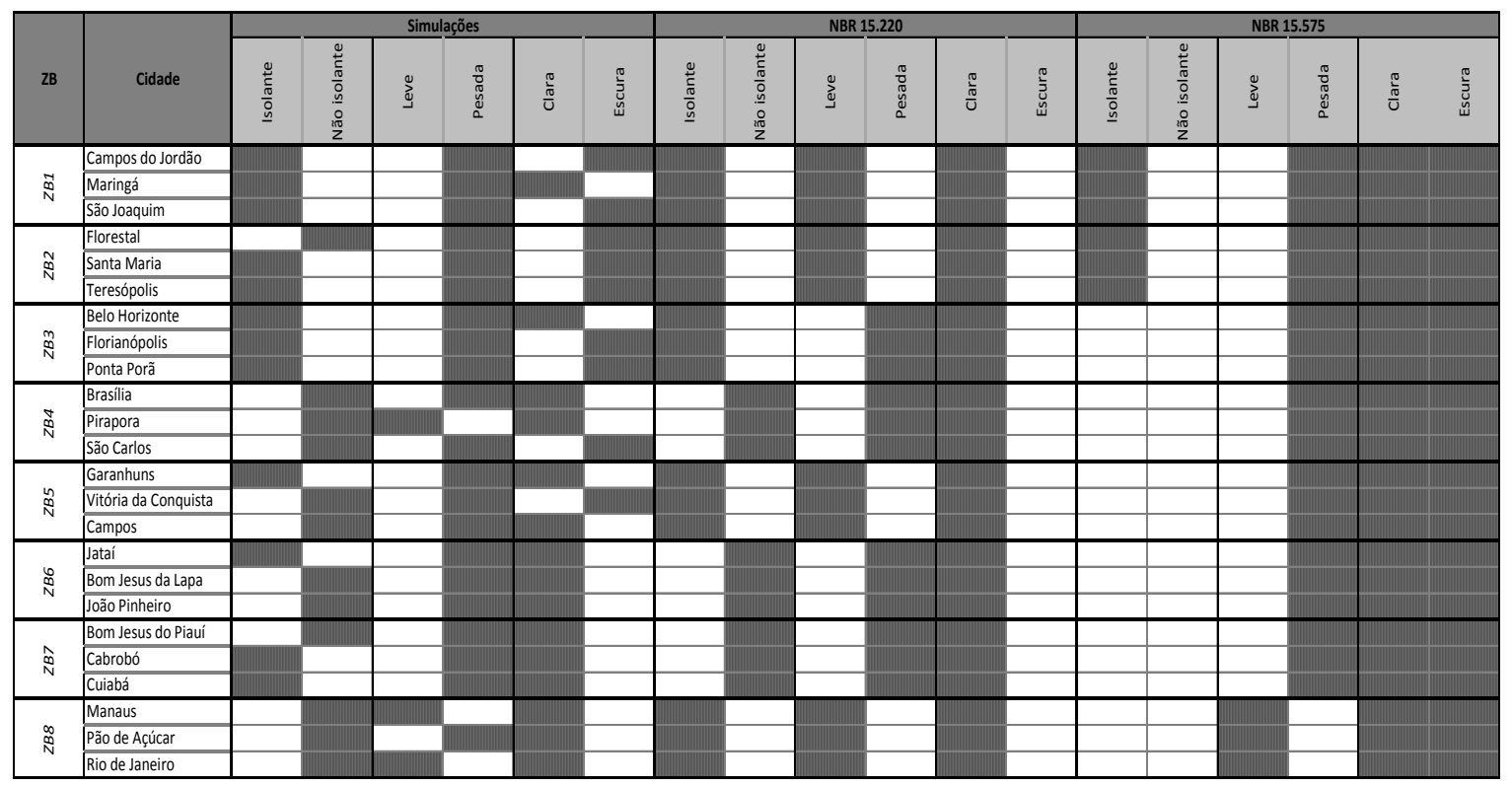

Quadro 2 - Resumo comparativo entre os resultados obtidos e os valores normativos para as coberturas

\begin{tabular}{|c|c|c|c|c|c|c|c|c|c|c|c|c|c|c|c|c|c|c|c|}
\hline \multirow[b]{2}{*}{ ZB } & \multirow[b]{2}{*}{ Cidade } & \multicolumn{6}{|c|}{ Simulaçōes } & \multicolumn{6}{|c|}{ NBR 15.220} & \multicolumn{6}{|c|}{ NBR 15.575 } \\
\hline & & $\begin{array}{l}\frac{\tilde{c}}{\tilde{c}} \\
\frac{0}{0} \\
\underline{0}\end{array}$ & $\begin{array}{l} \\
\frac{1}{0} \\
\frac{10}{0} \\
\frac{0}{20} \\
\frac{10}{2}\end{array}$ & $\sum_{0}^{0}$ & $\begin{array}{l}\frac{\pi}{0} \\
0 \\
0 \\
0\end{array}$ & $\frac{\frac{\pi}{\pi}}{\frac{\pi}{U}}$ & 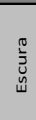 & $\begin{array}{l}\text { 总 } \\
\frac{0}{0} \\
\underline{\underline{0}}\end{array}$ & 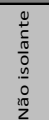 & ֻْ & $\begin{array}{l}\frac{\pi}{0} \\
0 \\
0 \\
0\end{array}$ & $\frac{\frac{\pi}{\pi}}{\frac{\pi}{U}}$ & 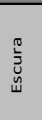 & $\begin{array}{l}\frac{0}{0} \\
\frac{0}{0} \\
\underline{\underline{0}}\end{array}$ & 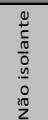 & 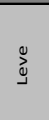 & $\begin{array}{l}\frac{\pi}{0} \\
0 \\
0 \\
0\end{array}$ & $\frac{\frac{\pi}{\pi}}{\frac{\pi}{U}}$ & $\begin{array}{l}\frac{0}{3} \\
\end{array}$ \\
\hline \multirow{3}{*}{$\stackrel{D}{N}$} & Campos do Jordão & & & & & & & & & & & & & & & & & & \\
\hline & Maringá & & & & & & & & & & & & & & & & & & \\
\hline & São Joaquim & & & & & & & & & & & & & & & & & & \\
\hline \multirow{3}{*}{$\stackrel{N}{N}$} & Florestal & & & & & & & & & & & & & & & & & & \\
\hline & Santa Maria & & & & & & & & & & & & & & & & & & \\
\hline & Teressópolis & & & & & & & & & & & & & & & & & & \\
\hline \multirow{3}{*}{ 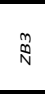 } & Belo Horizonte & & & & & & & & & & & & & & & & & & \\
\hline & Florianópolis & & & & & & & & & & & & & & & & & & \\
\hline & Ponta Porã & & & & & & & & & & & & & & & & & & \\
\hline \multirow{3}{*}{ D. } & Brasilia & & & & & & & & & & & & & & & & & & \\
\hline & Pirapora & & & & & & & & & & & & & & & & & & \\
\hline & Săo Carlos & & & & & & & & & & & & & & & & & & \\
\hline \multirow{3}{*}{$\stackrel{n}{N}$} & Garanhuns & & & & & & & & & & & & & & & & & & \\
\hline & Vitória da Conquist & & & & & & & & & & & & & & & & & & \\
\hline & Campos & & & & & & & & & & & & & & & & & & \\
\hline \multirow{3}{*}{ D. } & Jataí & & & & & & & & & & & & & & & & & & \\
\hline & Bom Jesus da Lapa & & & & & & & & & & & & & & & & & & \\
\hline & João Pinheiro & & & & & & & & & & & & & & & & & & \\
\hline \multirow{3}{*}{$\stackrel{\hat{N}}{N}$} & Bom Jesus do Piaúf & & & & & & & & & & & & & & & & & & \\
\hline & Cabrobó & & & & & & & & & & & & & & & & & & \\
\hline & Cuiabá & & & & & & & & & & & & & & & & & & \\
\hline \multirow{3}{*}{$\stackrel{\infty}{N}$} & Manaus & & & & & & & & & & & & & & & & & & \\
\hline & Pão de Ag̣úcar & & & & & & & & & & & & & & & & & & \\
\hline & Rio de Janeiro & & & & & & & & & & & & & & & & & & \\
\hline
\end{tabular}




\section{Conclusões}

As normas de desempenho térmico de edificações têm como objetivo avaliar a envoltória da edificação, identificando aquelas que irão garantir um desempenho térmico mínimo no qual seus usuários possam sentir-se em conforto. Atualmente vigoram no Brasil as normas de desempenho térmico NBR 15220 (ABNT, 2005) e a NBR 15575 (ABNT, 2013).

O presente trabalho comparou os resultados obtidos por simulação tendo como base um experimento fatorial com as recomendações normativas, que permitiram perceber algumas diferenças entre as recomendações normativas e os melhores desempenhos térmicos obtidos.

Em relação à norma NBR 15220 (ABNT, 2005), as paredes e coberturas apresentaram recomendações distintas entre a norma e as simulações. A norma recomenda paredes leves para as Zonas Bioclimáticas 1, 2, 3, 5 e 8, e pesadas para as Zonas Bioclimáticas 4,6 e 7 . Os resultados obtidos por simulação, por sua vez, indicaram que paredes pesadas são apropriadas para todas as zonas, com exceção da Zona Bioclimática 8 , sugerindo ser preciso rever os valores de atraso térmico estabelecidos. Além disso, para as Zonas Bioclimáticas 1, 2, 3 e 7 as paredes devem ser também isolantes.

As recomendações referentes às coberturas possuem mais semelhanças. Os resultados apontam que as coberturas devam ser quase sempre isolantes, assim como a norma NBR 15220 (ABNT, 2005) também recomenda, exceto nas Zonas Bioclimáticas 7 e 8 . Enquanto a norma recomenda coberturas pesadas para a Zona Bioclimática 7, as simulações indicaram coberturas leves e isolantes. Outro ponto é que para a Zona Bioclimática 8 a norma estabelece coberturas leves e refletoras, enquanto as simulações apontam por coberturas leves e isolantes.

Quanto à norma NBR 15575 (ABNT, 2013), merece ser ressaltada a permissividade para superfícies escuras. $\mathrm{O}$ estudo apontou que o emprego das superfícies escuras em climas que não sejam os frios pode comprometer bastante o desempenho térmico da edificação. Assim, a norma deveria coibir o uso de superfícies escuras $(\alpha>0,6)$ para qualquer localidade que pertença às Zonas Bioclimáticas 6,7 ou 8. Adicionalmente, é fundamental que a capacidade térmica das superfícies seja adequadamente estabelecida pela norma, uma vez que esta se mostrou determinante para as condições de conforto, bem mais que a transmitância térmica. Atualmente a única menção feita é a de que as paredes devem ter capacidade térmica superior a $130 \mathrm{~J} / \mathrm{m}^{2}$. No caso das coberturas, embora a capacidade térmica possua menor influência, sua definição se faz fundamental para se evitarem coberturas pesadas para climas quentes e que os valores-limite de transmitância térmica sejam mais restritivos.

Em resumo, o que se observou é que o atendimento aos requisitos normativos nem sempre garante condições de conforto térmico para alguns contextos climáticos, principalmente no caso da norma NBR 15575 (ABNT, 2013).

É preciso uma revisão do método de avaliação prescritivo das normas de desempenho que se baseiem fortemente na transmitância térmica da envoltória. No caso da cobertura não há problemas, mas no caso das paredes sim. É fundamental considerar a capacidade térmica dessas superfícies e as estratégias relacionadas, como a ventilação natural e o sombreamento, assim como coibir o uso de superfícies escuras senão para os climas frios. Ainda, os valores adotados para a transmitância térmica das paredes e coberturas nas normas mostraram-se muito elevados, enquanto os valores da capacidade térmica das paredes são mais baixos do que o indicado para garantir o melhor desempenho térmico da edificação.

\section{Referências}

AKUTSU, M.; VITTORINO, F. A Tendência Atual dos Métodos de Avaliação do Desempenho Térmico e Energético de Edificações. In: ENCONTRO NACIONAL DE CONFORTO NO AMBIENTE CONSTRUÍDO, 4., Salvador, 1997. Anais... Salvador: ANTAC, 1997.

AMERICAN SOCIETY FOR HEATING, REFRIGERATING AND AIR CONDITIONING. ASHRAE 55: thermal environmental conditions for human occupancy. Atlanta, 2013.

\section{ASSOCIAÇÃO BRASILEIRA DE NORMAS}

TÉCNICAS. NBR 15220: desempenho térmico de edificações. Rio de Janeiro, 2005.

ASSOCIAÇÃO BRASILEIRA DE NORMAS TÉCNICAS. NBR 15575: edifícios habitacionais: desempenho. Rio de Janeiro, 2013.

BARRIOS, G.; HUELSZ, G.; RECHTMAN, R. Wall/Roof Thermal Performance Differences Between Air-Conditioned and Non-Conditioned Rooms. Energy and Buildings, v. 43, n. 1, p. 219223, 2011. 
BOGO, A. J. Limitações Quanto aos Parâmetros de Desempenho Térmico e Estratégias Bioclimáticas Recomendadas Pela Norma Brasileira de Desempenho Térmico de Habitações de Interesse Social. São Paulo: Núcleo de Pesquisa em Tecnologia da Arquitetura e Urbanismo da Universidade de São Paulo, 2008.

CHVATAL, K. M. S. Avaliação do Procedimento Simplificado da NBR 15575 Para Determinação do Nível de Desempenho Térmico de Habitações. Ambiente Construído, Porto Alegre, v. 14, n. 4, p. 119-134, out./dez. 2014.

DEDEAR, R.; BRAGER, G. S. Thermal Comfort in Naturally Ventilated Buildings: revisions to ASHRAE Standard 55. Energy and Buildings, v. 34, p. 549-564, 2002.

ENCINAS, F.; HERDE, A. D. Sensitivity Analysis en Building Perfomance Simulation for Summer Comfort aSsessment of Apartments From the Real Estate Market. Energy and Buildings, v. 65, p. 55-65, 2013.

FERREIRA, C. C.; SOUZA, H. A.; ASSIS, E. S. D. Comparação de Desempenho de Envoltórias Recomendadas Por Normas de Desempenho e Mahoney. In: ENCONTRO NACIONAL E LATINOAMERICANO DE CONFORTO DO AMBIENTE CONSTRUÍDO, 13., Campinas, 2015. Anais... Campinas: ANTAC, 2015.

HYGH, J. S. et al. Multivariate Regression as an Energy Assessment Tool in Early Building Design. Building and Environment, v. 57, p. 165-175, 2012.

INSTITUTO NACIONAL DE METEOROLOGIA [Pesquisa]. Disponível em:

<http://www.inmet.gov.br/projetos/rede/pesquisa/> . Acesso em: 26 out. 2013.

KOENIGSBERGER, O. H.; MAHONEY, C.; EVANS, J. M. Climate and House Design. New York: United Nations, 1970.

MARA, T. A.; TARANTOLA, S. Application of Global Sensitivity Analysis of Model Output to Building Thermal Simulations. Building Simulation, v. 1, n. 4, p. 290-302, 2008.

MATOS, M. Simulação Computacional do Desempenho Térmico de Residências em Florianópolis Utilizando a Ventilação Natural. Florianópolis, 2007. 108 f. Dissertação (Mestrado em Engenharia Civil) - Programa de PósGraduação em Engenharia Civil, Universidade Federal de Santa Catarina, Florianópolis, 2007.

MONTGOMERY, D. C.; RUNGER, G. C.; HUBELE, N. F. Estatística Aplicada à Engenharia. 2. ed. Rio de Janeiro: Livros Técnicos e Científicos, 2012.
MORISHITA, C. et al. Catálogo de Propriedades Térmicas de Paredes e Coberturas.

Florianópolis: Laboratório em Edificações do Departamento de Engenharia Civil da UFSC, 2013.

OLIVEIRA, L. D. S. Avaliação dos Limites das Propriedades Térmicas dos Fechamentos Opacos da NBR 15220-3 Para Habitações de Interesse Social, da Zona Bioclimática 2. Pelotas, 2012. 156 f. Dissertação (Mestrado em Arquitetura e Urbanismo) - Pós-Graduação em Arquitetura e Urbanismo, Universidade Federal de Pelotas, Pelotas, 2012.

ORDENES, M. et al. Metodologia Utilizada na Elaboração da Biblioteca de Materiais e Componentes Construtivos Brasileiros Para Simulações no VisualDOE 3.1. Florianópolis: Universidade Federal de Santa Catarina, 2013. Relatório Interno - Departamento de Engenharia Civil.

PEREIRA, C. D. A Influência do Envelope no Desempenho Térmico de Edificações

Residenciais Unifamiliares Ocupadas e Ventiladas Naturalmente. Florianópolis, 2009. 141 f. Dissertação (Mestrado em Engenharia Civil) - Programa de Pós-Graduação em Engenharia Civil, Universidade Federal de Santa Catarina, Florianópolis, 2009.

PEREIRA, I.; ASSIS, E. S. Discussão das Estratégias Propostas Pelo Projeto de Norma de Desempenho Térmico de Edificações Através de Estudo de Caso. In: ENCONTRO LATINO, 4.; ENCONTRO NACIONAL DE CONFORTO NO AMBIENTE CONSTRUÍDO, 8., Maceió, 2005. Anais... Maceió: ANTAC, 2005.

PEREIRA, I. M.; FERREIRA, C. C. Avaliação dos Impactos da ABNT NBR 15575 no Conforto Térmico e no Consumo de Energias nas Novas Edificações Habitacionais Brasileiras. In: ENCONTRO NACIONAL DE TECNOLOGIA DO AMBIENTE CONSTRUÍDO, 15., Maceió, 2014. Anais... Maceió: ANTAC, 2014.

REDDY, T. A. Applied Data Analysis and Modeling for Energy Engineers and Scientists. New York: Spinger Science \& Business Media, 2011.

RORIZ, M. Arquivos Climáticos de Municípios Brasileiros. In: ASSOCIAÇÃO NACIONAL DE TECNOLOGIA DO AMBIENTE CONSTRUÍDO. Grupo de Trabalho sobre Conforto e Eficiência Energética de Edificações. São Carlos, 2012. 
SALTELLI, A.; TARANTOLA, S.;

CAMPOLONGO, F. Sensitivity Analysis as an Ingredient of Modeling. Statistical Science, v. 15, n. 4, p. 377-395, 2000.

SILVA, A. S.; GHISI, E. Análise de Sensibilidade Global dos Parâmetros Termofísicos de Uma Edificação Residencial de Acordo Com o Método de Simulação do RTQ-R. Ambiente Construído, Porto Alegre, v. 13, n. 4, p. 135-148, out./dez. 2013.

\section{SOARES, M. M. Avaliação dos Parâmetros de} Desempenho Térmico da NBR 15575/2013:

habitações de interesse social na zona bioclimática 2. Pelotas, 2014. 159 f. Dissertação (Mestrado em Arquitetura e Urbanismo) - Pós-Graduação em Arquitetura e Urbanismo, Universidade Federal de Pelotas, Pelotas, 2014.
TIAN, W. A Reviewm of Sensitivity Analysis Methods in Building Energy Analysis. Renewable and Sustainable Energy Reviews, v. 20, p. 411419, 2013.

\section{Agradecimentos}

Os autores agradecem o apoio financeiro da Coordenação de Aperfeiçoamento de Pessoal de Nível Superior (Capes) e ao Conselho Nacional de Desenvolvimento Científico e Tecnológico $(\mathrm{CNPq})$.

\section{Camila Carvalho Ferrreira}

Departamento de Sistemas de Produção | Universidade Estadual de Minas Gerais | Av. Antônio Carlos, 7545, São Luiz | Belo Horizonte MG - Brasil | CEP 31270-010 | Tel.: (31) 3439-6524 | E-mail: camilaccferreira@yahoo.com.br

\section{Henor Artur de Souza}

Departamento d eEngenharia de Controle e Automação e Técnicas Fundamentais, Escola de Minas | Universidade Federal de Ouro Preto | Campus Universitário s/n, Morro do Cruzeiro | Ouro Preto - MG - Brasil | CEP 35400-000 | Tel.: (31) 3559-1533 Ramal 1482 |

E-mail: henorster@gmail.com

\section{Eleonora Sad de Assis}

Departamento de Tecnologia da Arquitetura e do Urbanismo | Universidade Federal de Minas Gerais | Rua Paraíba, 697, Funcionários | Belo Horizonte - MG - Brasil | CEP 30130-140 | Tel.: (31) 3409-8873 | E-mail: eleonorasad@yahoo.com.br

\section{Revista Ambiente Construído}

Associação Nacional de Tecnologia do Ambiente Construído

Av. Osvaldo Aranha, $99-3^{\circ}$ andar, Centro

Porto Alegre - RS - Brasil

CEP $90035-190$

Telefone: +55 (51) 3308-4084

Fax: +55 (51) 3308-4054

www.seer.ufrgs.br/ambienteconstruido

E-mail: ambienteconstruido@ufrgs.br 